NBER WORKING PAPER SERIES

\title{
INTERNATIONAL LENDING OF LAST RESORT \\ AND MORAL HAZARD: A MODEL OF IMF'S CATALYTIC FINANCE
}

\author{
Giancarlo Corsetti \\ Bernardo Guimaraes \\ Nouriel Roubini \\ Working Paper 10125 \\ http://www.nber.org/papers/w10125
NATIONAL BUREAU OF ECONOMIC RESEARCH
1050 Massachusetts Avenue
Cambridge, MA 02138
December 2003

\begin{abstract}
We thank for comments Casper De Vries, Olivier Jeanne, Stephen Morris, Adrian Penalver, and seminar participants at the Bank of Italy, ESSIM 2003, the International Monetary Fund, the "34th Konstanz Seminar on Monetary Theory and Monetary Policy", 2003 LACEA conference, New York University and the Federal Reserve Board. Corsetti's work on this paper is part of the Research Network on 'The Analysis of International Capital Markets: Understanding Europe's Role in the Global Economy', funded by the European Commission under the Research Training Network Programme (Contract No. HPRN-CT-1999-00067). Corsetti gratefully acknowledges the European Central Bank for hospitality when working on this project. Correspondence: giancarlo.corsetti@iue.it; bernardo.guimaraes@yale.edu; nroubini@stern.nyu.edu.The views expressed herein are those of the authors and not necessarily those of the National Bureau of Economic Research.
\end{abstract}

(C2003 by Giancarlo Corsetti, Bernardo Guimaraes, and Nouriel Roubini. All rights reserved. Short sections of text, not to exceed two paragraphs, may be quoted without explicit permission provided that full credit, including (C) notice, is given to the source. 
International Lending of Last Resort and Moral Hazard: A Model of IMF's Catalytic Finance

Giancarlo Corsetti, Bernardo Guimaraes, and Nouriel Roubini

NBER Working Paper No. 10125

December 2003

JEL No. F33, F34, N20

\begin{abstract}
It is often argued that the provision of liquidity by the international institutions such as the IMF to countries experiencing balance of payment problems can have catalytic effects on the behavior of international financial markets, i.e., it can reduce the scale of liquidity runs by inducing investors to roll over their financial claims to the country. Critics point out that official lending also causes moral hazard distortions: expecting to be bailed out by the IMF, debtor countries have weak incentives to implement good but costly policies, thus raising the probability of a crisis. This paper presents an analytical framework to study the trade-off between official liquidity provision and debtor moral hazard. In our model international financial crises are caused by the interaction of bad fundamentals, self-fulfilling runs and policies by three classes of optimizing agents: international investors, the local government and the IMF. We show how an international financial institution helps prevent liquidity runs via coordination of agents' expectations, by raising the number of investors willing to lend to the country for any given level of the fundamental. We show that the influence of such an institution is increasing in the size of its interventions and the precision of its information: more liquidity support and better information make agents more willing to roll over their debt and reduces the probability of a crisis. Different from the conventional view stressing debtor moral hazard, we show that official lending may actually strengthen a government incentive to implement desirable but costly policies. By worsening the expected return on these policies, destructive liquidity runs may well discourage governments from undertaking them, unless they can count on contingent liquidity assistance.
\end{abstract}

Giancarlo Corsetti

European University Institute

corsetti@iue.it

Bernardo Guimaraes

Yale University

bernardo.guimaraes@yale.edu
Nouriel Roubini

Department of Economics, KMC 7-83

Stern School of Business

New York University

44 West 4th Street

New York, NY 10012

nroubini@stern.nyu.edu 


\section{Introduction}

In the last decade many emerging market economies have experienced currency, debt, financial and banking crises: Mexico, Thailand, Indonesia, Korea, Russia, Brazil, Ecuador, Turkey, Argentina and Uruguay, to name the main ones. At different times, each of these countries faced massive reversal of capital flows, and experienced a large drop in asset prices and economic activity. Even if current account deficits were sharply reduced via domestic policy adjustment and painful economic contraction, external financing gaps remained large because of strong capital outflows and the unwillingness of investors to rollover short-term claims on the country (including its government, its banks and its residents).

Crisis resolution has thus involved, in addition to domestic policy adjustment, some combination of official financing (or 'bailouts') by International Financial Institutions and other official creditors, and private financing in the form of 'bailins' of private investors (the latter is also referred to as private sector involvement (or PSI) in crisis resolution). ${ }^{1}$ Indeed, the issue of 'bailouts' versus 'bailins' - or private sector involvement in crisis resolution - is the most controversial question in the debate on the reform of the international financial architecture. ${ }^{2}$

In this debate, an important view holds that international currency and financial crises are primarily driven by liquidity runs and panics, and could therefore be avoided via the provision of sufficient international liquidity to countries threatened by a crisis. According to this view, the global financial architecture should be reformed by creating an international lender of last resort. Not only would such an institution increase efficiency ex-post by eliminating liquidation costs and default in the event of a run: by severing the link between illiquidity and insolvency, it would also prevent crises from occurring in the first place (see Sachs (1995) and Fischer (2001)). The opposing view doubts that international illiquidity is the main factor driving crises. When crises can also be attributed to fundamental shocks and policy mismanagement,

\footnotetext{
${ }^{1}$ Bail-ins can take various forms in a spectrum going from very coercive to very soft forms of PSI: at one extreme are defaults on external (and domestic) claims (as in the case of Ecuador, Argentina, Russia); somewhere between extremes are debt suspension and standstills, semi-coercive bonded debt exchange offers, semi-coercive rollover agreements (as in the case of Ukraine, Pakistan, Uruguay Korea, Indonesia, Thailand); on the softer corner of the PSI spectrum are semivoluntary rollover agreements and other mild forms of PSI (Brazil in 1999, Turkey in 2001) or outright bailouts with little PSI (Mexico in 1995, Turkey in 2002-2003).

${ }^{2}$ See Roubini (2001, 2002a, b, 2003) and Roubini and Setser (2003) for a detailed discussion of the PSI and "bail-in versus bail-out" debate.
} 
liquidity support may turn into a subsidy to insolvent countries, thus generating debtor and creditors moral hazard (see the Meltzer Commission Report (2001)). Accordingly, IMF interventions should be limited in frequency and size so as to reduce moral hazard distortions, even if limited support would not prevent liquidity runs.

The official IMF/G7 position is somewhere between the two extreme views described above: provided a crisis is closer to illiquidity than to insolvency, a partial bailout granted conditional on policy adjustment by the debtor country can restore investors' confidence and voluntary lending and therefore stop destructive runs - i.e., can have a "catalytic effect". If the "catalytic" approach is successful, official resources do not need to be unlimited (i.e., so large as to fill in any potential financing gap), since some official liquidity provision and policy adjustment will convince private investors to rollover their positions (rather than run) while restoring market access by the debtor country. ${ }^{3}$ But can partial "catalytic" bailouts be successful or, as argued by many, can only 'corner solutions' of large full bailouts or full bailins prevent destructive runs? And if bailouts are not desirable because of moral hazard distortions, shouldn't the IMF promote alternative mechanisms that can coordinate investors' behavior in the event of a crisis, such as debt suspension/standstill or temporary capital controls? ${ }^{4}$

This paper contributes to the current debate on these issues by providing a theoretical model of financial crises and the main policy trade-offs in the design of liquidity provision by an international financial institution. In our model, a crisis can be generated both by fundamental shocks and by self-fulfilling panics, whereas liquidity provision affects the optimal behavior of the government in the debtor country (possibly generating moral hazard distortions). Our study draws on the theoretical model by Corsetti, Dasgupta, Morris and Shin (2002) and the

\footnotetext{
${ }^{3}$ See Cottarelli and Giannini (2002) and Mody and Saravia (2003) for an analysis of the IMF's catalytic approach and an assessment of its success.

${ }^{4}$ On these controversial questions, there is a wide range of opinions, but little analytical and formal work. The G7 doctrine and framework for PSI policy has evolved over time as a reform of the international financial architecture was started after the Asian and global crisis of 1997-98. The current tentative but fragile G7/IMF consensus approach can be summarized as follows. Based on a case-by-case discretional assessment of each crisis, the IMF should finance troubled countries with large, possibly catalytic, packages when the crisis is closer to illiquidity and country policy adjustment can ensure solvency. The IMF should limit its financial support, and proceed with debt restructuring/reduction when a country is close to insolvency and unable to adopt adjustment policies. A combination of limited official financing, appropriate bailins (such as debt reprofiling, restretching or restructuring) and policy adjustment is appropriate in cases between the two extremes - whenever problems are more severe than illiquidity but not as severe as in insolvency. Clearly, many difficult issues are left open in this framework such as those related to when large catalytic finance is appropriate.
} 
policy analysis by Corsetti, Pesenti and Roubini (2002), on the role of large speculative traders in a currency crisis. Consistent with these contributions, we model the official creditor (the IMF or ILOLR) as a large player in the world economy, with a well-defined objective function and financial resources. In our model, the strategies of the official creditor, international speculators and domestic governments are all endogenously determined in equilibrium.

There are two major areas in which our model contributes to the debate on the reform of the international financial architecture: the effectiveness of catalytic finance and the trade-off between liquidity support and moral hazard distortions. As regards the first area, our analysis lends support to the hypothesis that catalytic liquidity provision by an official institution can work to prevent a destructive run - although in our model the success of partial bailouts is realistically limited to cases in which macroeconomic fundamentals are not too weak. In reality, the IMF does not have infinite resources and cannot close by itself the possibly very large external financing gaps generated by speculative runs, i.e., the IMF cannot rule out debt defaults due to illiquidity runs. According to our results, however, even when relatively small, contingent liquidity support lowers the likelihood of a crisis by enlarging the range of economic fundamentals at which international investors find it optimal to rollover their credit to the country. This 'catalytic effect' is stronger, the larger the size of IMF funds, and the more accurate the IMF information. But our results also make clear that catalytic finance cannot and will not be effective when the fundamental turns out to be very weak ex post: as more and more agents receive bad signals about the state of the economy, massive withdrawals will cause a crisis regardless of whether the IMF intervenes.

Our result runs counter to the hypothesis, first suggested by Krugman and King and then formalized by Zettelmeyer (1999) and Wyplosz and Jeanne (2000), that IMF bailouts can be effective only when there are enough resources to fill financing gaps of any possible size. These authors base their view on models with multiple equilibria, in which partial bailouts cannot rule out the possibility of self-fulfilling runs, i.e., partial IMF interventions are not an effective coordination mechanism of private investors. In such a framework, liquidity support is effective only insofar as it is large enough to prevent a run and eliminate all liquidation costs in the presence of a run. ${ }^{5}$

\footnotetext{
${ }^{5}$ Models drawing on the traditional bank run literature prescribe that the IMF should have very deep pockets. Usually, in the analysis underlying such a view, the cost of a crisis is independent of the size of the financial gap, i.e. the difference
} 
Building on the main insights from the literature on global games, ${ }^{6}$ our paper contributes to our understanding of how and why catalytic finance can work. Liquidity support is effective both directly and indirectly. Directly, it reduces liquidation costs against speculative withdrawal of credit as liquidity provision reduces the amount of illiquid investments that need to be liquidated. Indirectly, it reduces the number of speculators willing to attack a country for each realization of the economic fundamentals. In other words, the presence of the IMF means that, over some crucial range of fundamentals, private investors are more likely to rollover their positions than roll them off - this is the essence of 'catalytic finance.'

Second, contrary to the widespread view linking provision of liquidity to moral hazard distortions, we show that under some circumstances liquidity assistance can actually make a government willing to implement efficiency-enhancing but costly reforms. More specifically, the conventional view on debtor moral hazard is that, by insulating the macroeconomic outcome from ruinous speculative runs, liquidity assistance gives the government an incentive to avoid the costs of implementing good policies. But this is not the only possible effect of an ILOLR. It is also plausible that some governments may be discouraged from implementing good but costly policies because speculative runs may jeopardize their success. In this scenario, by reducing liquidation costs in the event of a run, liquidity support actually enables a government to implement socially desirable policies, i.e., official support motivates a country to follow good policies. Our model can generate both scenarios - one with debtor moral hazard distortions in case of large liquidity support, the other one with complementarity between liquidity assistance and good policy behavior.

Our analysis is related to a vast and fast-growing literature on the merits of bailouts vs. bailins as a crisis resolution strategy and the arguments in favor of an ILOLR (surveyed in

between short term obligations and the liquid financial resources available to the country. In other words, by falling either one cent or one billion dollars short of obligations, the country pays the same large cost. More general and realistic models - such as that in our paper - would allow for partial liquidation of long term investment (selling one bit of it may provide the required resources without incurring a macroeconomic crisis). See appendix A of this paper for further discussion.

${ }^{6}$ Specifically, our framework draws on the literature on global games as developed by Carlsson and van Damme (1993) and Morris and Shin (2000). As is well known, in global games the state of the economy and speculative activity is not common knowledge among agents. With asymmetric information, there will be some heterogeneity in speculative positions even if everybody follows the same optimal strategy in equilibrium. Moreover, the precision of information need not be the same across individuals. Arguably, global games provide a particularly attractive framework to analyze the coordination problem in financial markets. 
section 2 below). Our paper contributes to this literature in a number of dimensions.

First, most papers analyze an ILOLR in models after Diamond and Dybvig (1983) D\&D henceforth - interpreting crises as a switch across instantaneous (rational-expectations) equilibria, but ignoring or downplaying macroeconomic shocks or any other risk of fundamental insolvency. In contrast, we develop a model where a crisis may be anywhere in the spectrum going from pure illiquidity to insolvency. Thus, we present a more realistic specification of an open economy where fundamentals, in additions to speculation, can cause debt crises. ${ }^{7}$

Second, contributions drawing on D\&D cannot properly address issues in moral hazard by liquidity provisions. The reason is that, in models of multiple equilibria, the results of comparative static analysis depend on which equilibrium is selected, but there is no endogenous mechanism that leads agents to select one equilibrium over the other(s). In contrast, in our global games model the coordination mechanism is endogenous, and the equilibrium is unique. We can therefore perform comparative statics analysis, tracing the effect on government behavior of various assumptions about the size of the IMF, the precision of its information and other parameters of the model. As already mentioned, the conventional wisdom is that official finance exacerbates the moral hazard problem: the novel result from our analysis is that, in some circumstances, the existence of official liquidity assistance can give a debtor country the right incentive to implement policy adjustment.

Third, in the context of global games and the literature on the ILOLR building on them (see Morris and Shin (2002) but also the closed-economy model by Goldstein and Pauzner (2002) and Rochet and Vives (2002)) we model the role of official financial institutions as large players whose behavior is endogenously derived in equilibrium. Much of our new analytical insight stems exactly from this original feature of our model. In specifying the preferences of its shareholders or principals, we model a 'conservative' IMF, in the sense that it seeks to lend to illiquid countries, but not to insolvent countries. Consistently, in our equilibrium the IMF is more likely to provide liquidity support when the crisis is caused by a liquidity run, as opposed to crises that are closer to the case of insolvency.

Fourth, in our framework domestic expected GNP is a natural measure for national welfare - which may differ from the objective function of the domestic government because of the (political) costs of implementing reforms and adjustment policies. We can therefore analyze

\footnotetext{
${ }^{7}$ Thus, our model is closer to fundamental banking crisis models a' la Allen and Gale (2000) rather than D\&D models.
} 
the impact on the welfare of domestic citizens and the government of alternative intervention strategies by the IMF.

Fifth, the framework of global games allows us to assess the role of IMF information precision in strengthening the IMF's influence on private investors' strategies and government behavior. In general, a better-informed IMF reduces the aggressiveness of private speculators, and therefore lowers the likelihood of a crisis. The role of information precision in catalytic finance, however, becomes much more important when the IMF can strategically signal its position to the market, e.g. it can choose to move before private investors. Some results on signalling by CDMS and Dasgupta (1999) indeed suggest that in our economy there is an equilibrium in which the IMF has a much stronger impact on market behavior by moving before private investors. As in Dasgupta (1999), an IMF with sufficiently precise information can induce 'strong herding behavior' - i.e., private funds' managers disregard their private information and make their portfolio conditional on the IMF move, rolling over their debt if the IMF makes liquidity available to the country, withdrawing otherwise.

The structure of the paper is as follows. Section 2 below briefly surveys the literature on liquidity provision, catalytic finance and moral hazard. Section 3 introduces the model. Sections 4, 5 and 6 present our main results, regarding the effect of IMF lending on the likelihood and severity of crises and the trade-off between IMF assistance and moral hazard distortions. Section 7 discusses two extensions of the model, namely, seniority of IMF loans and different timing of IMF interventions. Section 8 concludes.

\section{The international lender of last resort and "catalytic" fi- nance: an overview of issues in theory and policy}

In this section, we briefly discuss the debate on the creation of an international lender of last resort (ILOLR), and the role of IMF lending as a "catalyst" for private lending at the onset and during a crisis. This literature presents views and approaches which stress different market failures underlying financial crises, and therefore emphasize different policy trade-offs faced by governments and international institutions.

Sachs (1984) among others ${ }^{8}$ has emphasized the possibility of panic-driven runs of creditors

\footnotetext{
${ }^{8}$ Many open economy models of bank or debt runs (such as Chang and Velasco (1999) and Cole and Kehoe (1998)) are
} 
when the country's liquid assets fall short of the country's short-term liabilities (including short-term debt, long-term debt coming to maturity, and interest payments). Models with multiple instantaneous equilibria suggest that, provided that fundamentals are not too strong, these runs may occur in either bad or good states of the world, and independently of the policies implemented by the debtor country.

The literature has typically provided examples in which liquidity runs cause default because of the implied liquidation costs. In these examples, if creditors could be convinced to rollover debt, wasteful costs and default could be avoided altogether. But it is important to stress that liquidity runs are costly also in bad states of the world, whereas the country would be bankrupt independently of a run. In this case coordination failures among creditors creates additional, avoidable costs on top of the costs due to bad shocks to fundamentals.

The possibility of coordination problems among creditors is the main argument in favor of an international lender of last resort (ILOLR). ${ }^{9}$ To assess the strength of this argument it is useful to understand in detail the conditions under which, facing a liquidity run, a country is unable to obtain new loans. As there is no shortage of liquidity in international markets, it must be that either (a) there is no private lender that is large enough to solve by itself the coordination problem and finance a potentially solvent debtor, or (b) uncertainty and incomplete information about the fundamentals of the country generate doubts about its solvency.

The latter point is key in any discussion of the ILOLR, as full ILOLR support is warranted only in the presence of pure liquidity problems. The important point here is that there is almost no historical example of pure liquidity-driven crises. Countries in financial difficulties usually have weak fundamentals and serious policy shortcomings prior to the run. ${ }^{10}$ This evidence casts doubts on policy implications derived from models where crises are generated

international variants of the Diamond and Dybvig (1983) and Bryant (1980) models of bank runs.

${ }^{9}$ See Sachs (1995) for an argument in favor of an ILOLR along such lines and see Fischer (2001) for reasons underlying the creation of an ILOLR. In models after Diamond-Dybvig, self-fulfilling bank runs can be ruled out by the existence of a lender of last resort providing unlimited liquidity support, or even a (government) guarantee on deposits, i.e. deposit insurance. Jeanne (2000) argues that global welfare is increased through ILOLR intervention. Moral hazard issues are finessed in the ILOLR model of Jeanne and Wyplosz (2001) as well as in many other analytical contributions to the ILOLR debate.

${ }^{10}$ Empirically, illiquidity problems characterize countries also experiencing some fundamental or policy weaknesses. In cases like Mexico, Korea, Brazil, Thailand, Indonesia and Uruguay, one can argue that the immediate cause of the crisis was indeed a liquidity problem. Yet some serious macro, structural or policy shortcomings certainly played a role in triggering the crisis. And in some cases (e.g. Argentina in 2001) illiquidity interacted with deeper solvency issues. 
exclusively by speculative runs (usually a variant of the Diamond and Dybvig model), since these analyses justify an ILOLR by construction. It is preferable to build models where the country is exposed to fundamental risk, which may cause default independently of a run, and study the coordination problems of investors who face strategic uncertainty about both the fundamentals and each other's behavior. ${ }^{11}$ This is the approach we take in our paper. ${ }^{12}$

Moreover, even in cases that are close to a pure speculative run, it could be argued that the amount of official support need not be unlimited, i.e., need not be equal the external financing gap: the combination of an official package and strong domestic policy to signal commitment to service the country debt should restore investor's confidence and therefore the country's access to international financial markets. The external financing gap will therefore be closed by both official loans and new (voluntary) private capital flows.

The model of catalytic finance shapes the traditional, official view of liquidity provision by the IMF. Yet, until very recently, there was no theoretical analysis of why and how catalytic finance could work. The literature mostly focused on the corner solutions of full bailins or full bailouts. This paper and Morris and Shin (2002) are, to our knowledge, the first contributions to fill such gap in the literature (see also the closed-economy model by Rochet and Vives (2002)).

The core policy tradeoff in creating an ILOLR is between liquidity provision and moral hazard distortions. For instance, in analyzing the IMF role in the new international financial architecture, many authors have stressed the need to complement provision of liquidity with punishment mechanisms that reduce the incentive to default strategically (as in Dooley and

\footnotetext{
${ }^{11}$ In the bank run literature, there are several models of bank runs and crises driven by fundamentals. An incomplete list includes Allen and Gale (2000), Jacklin and Bhattacharya (1988) and Gorton (1987).

${ }^{12}$ Note that the argument in favor of a "full bailout" by an ILOLR could also be used in support of a "full bail-in", i.e. some combination of broad debt standstills/suspension, capital controls and other measures to lock in all investors who are rushing to the door. Diamond and Dybvig (1983) for instance suggest that a temporary debt suspension (bank holiday) is the optimal policy to prevent multiple equilibria runs. The two solutions are not equivalent, however, except under special circumstances. They have different merits, depending on several features of the economy including the importance of fundamental problems potentially jeopardizing solvency, the degree of uncertainty and precision of private information about the fundamentals and the policy response to the crisis, and creditors' risk-aversion - see for instance the discussion in Frankel and Roubini (2001), and Roubini (2000, 2002b) arguing in favor of "bailouts" rather than debt-suspension solution to liqudity crises and Wallace (1988) stressing optimal debt suspension policy. Debt standstill/suspensions as alternative policies to catalytic official finance as crisis resolution tools have not yet been analyzed in much formal detail in the literature. A partial exception is Bank of England (2002).
} 
Verma (2000)) or tune down policy efforts to ensure solvency (as in Kumar, Masson and Miller (2000)). Specifically, Dooley and Verma (2000) strongly argued against reducing the costs of renegotiating debt. To the extent that this leads an opportunistic sovereign to use debt suspensions/standstill/defaults too often, the flow of capital to emerging markets would drop to socially inefficient levels in equilibrium (see also Gai, Hayes and Shin (2001) for a refinement of the argument).

In a closed economy setup, moral hazard distortions can be reduced via incentive-compatible deposit insurance, capital adequacy regulation and overall supervision and regulation of the banking sector. In case financial distress occurs, the central bank and/or the authorities in charge of regulation and supervision have the power to seize the banks, change their management, restructure and merge them with other banks or even liquidate them. But in an international context, there is no international authority with comparable powers: debtors with sovereign immunity cannot be seized, merged or closed down. Moral hazard distortions deriving from the existence of an ILOLR are thus potentially exacerbated. ${ }^{13}$

Some recent literature has contributed to our understanding of the policy trade-offs between liquidity and moral hazard. Bank of England (2002) present a model that allows for fundamentals-driven runs, and assess the arguments in favor debt standstills, relative to official finance, as crisis resolution mechanisms. These authors discuss the implications of moral hazard but do not develop a model of the tradeoff between these objectives and the optimal

\footnotetext{
${ }^{13} \mathrm{~A}$ number of recent contributions have discussed several dimensions of this issue. Kumar, Masson and Miller (2000) focus on the maturity structure of external debt: short-term debt imposes discipline on the debtor, but only at the cost of raising the probability of self-fulfilling runs. In this model, moral hazard distortions imply that full insurance by international institutions is never optimal. Rather, liquidity lending should be made conditional on policy/effort changes that can be effectively monitored by the IMF.

The accuracy of the IMF information is an important issue in assessing whether liquidity provision is appropriate or not and whether it exacerbates moral hazard distortions. Gai, Hayes and Shin (2001) model the IMF role in reducing the costs of disorderly adjustment following debt servicing difficulties in the presence of debtor moral hazard. International liquidity support is more likely to be beneficial if the IMF can make an accurate assessment of the country's policy efforts. If the IMF is not very effective in distinguishing between a crisis due to bad luck and a crisis due to opportunistic default, lowering the ex-post cost of a crisis will raise the incentive to default strategically. In equilibrium a larger role for the IMF can reduce social welfare because it leads to a sizeable drop in the amount of international lending. As argued by Ghosal and Miller (2002), if official creditors cannot detect the nature of the crisis (insolvency versus opportunistic/moral hazard-driven default), there is a case for "constructive ambiguity", i.e. there should be some uncertainty about the provision of official liquidity support as a way to reduce moral hazard distortions. In our model, we formally analyze the role of the relative informational advantage of an official creditor relative to the private ones.
} 
intervention policy. Gale and Vives (2002) study the role of dollarization in overcoming moral hazard distortions deriving from domestic (but not international) bailout mechanisms (such as central bank injection of liquidity in a banking system subject to a run). Allen and Gale (2000a) introduce moral hazard distortions in a model of fundamental bank runs, but do not consider analytically the role of an international lender of last resort. Vives and Rochet (2002) study domestic lending of last resort as a solution to bank runs in a global game model. ${ }^{14}$ They find that liquidity and solvency regulation can solve the creditor coordination problem that leads to runs but that their cost is too high in terms of foregone returns. Thus, emergency liquidity support is optimal in addition to such regulations. However, they do not model the lender of last resort as a player - as we do in our paper. Therefore, they do not analyze the tradeoff between bailouts and moral hazard, and the role of a large official creditor (IMF) that is central to our study. The closest analysis to our model is that of Morris and Shin (2002) who, in a parallel contribution, also consider formally catalytic IMF finance - although they do not model the IMF as a 'large player'. ${ }^{15}$

\section{The model}

Consider a small open economy with a three-period horizon — periods are denoted 0,1 (or interim) and 2. The economy is populated by a continuum of agents of mass 1 , each endowed with $E$ units of resources. These agents can borrow up to $D$ from a continuum of international fund managers also of mass 1 , willing to lend to the country only short term. Moreover, there exists one international financial institution, the International Monetary Fund (IMF), which may provide the country with international liquidity up to L. For simplicity, all international lending and borrowing by domestic agents takes place at the same international interest rate $r^{*}$, which is normalized to zero.

Domestic agents invest in domestic projects which yield a stochastic rate of return equal to $R$ in period 2 , or to $R /(1+\kappa)$ if projects are discontinued and liquidated early in the interim

\footnotetext{
${ }^{14}$ See also Goldstein and Pauzner (2002).

${ }^{15}$ Several recent studies (Cottarelli and Giannini (2001), Mody and Saravia (2003) and Roubini and Setser (2003)) have provided useful empirical evidence on catalytic finance. According to these studies, and consistent with the main results of our analysis, catalytic finance is more likely to be sucessful when fundamentals are not bad and/or the amount of policy adjustment required to achieve debt sustainability is feasible and credible.
} 
period. The expected return from these projects in period 2 is well above the international interest rate, i.e., $E_{0} R>1+r^{*}=1$. Yet, investment is illiquid, in the sense that projects can be discontinued in period 1 at the cost $\kappa>0$ per unit of investment. ${ }^{16}$

The sequence of decisions can be summarized as follows. In period 0 , agents in the economy invest their own endowment and the borrowed resources $E+D$ in the domestic risky technology $I$ and in an international liquid asset $M$.

In the interim period, fund managers decide whether to rollover their loans or withdraw. Denoting with $x$ the fraction of managers who decide to withdraw, $x D$ measures the shortterm liquidity need of the country. To meet short-term obligations, domestic agents can use their stock of liquid resources, and can liquidate some fraction $z$ of the long term investment $I$, getting $z R I /(1+\kappa)$. In addition, if the IMF decides to intervenes, the country can obtain funds up to $L$.

Let $\Lambda$ denote total international liquidity available to the country, including both the predetermined component $M$ and the contingent component $L$. Clearly, the country will incur some liquidation costs when $x D>\Lambda$ (i.e., $z$ will be such that $x D-\Lambda=z R I /(1+\kappa)$ ); it will default when $x D>\Lambda+R I /(1+\kappa)$ (i.e., domestic agents will not be able to meet their short-term obligations despite complete liquidation of long-term investment). When the country defaults, we assume that all lenders will be paid pro-rata, up to exhausting the resources available to the country.

In the last period, the country total resources consist of $R(1-z) I$ (corresponding to GDP), plus any money left over from the previous period, i.e., $\max \{\Lambda-x D, 0\}$. Its liabilities consists of private debt $(1-x) D$ plus any outstanding IMF loan $L$. As for the case of default in the interim period, we assume that lenders are treated symmetrically and paid pro-rata also when the country defaults in period 2 (the case in which IMF loans have priority over private loans is discussed in one of the extensions of the model presented in Section 7).

\footnotetext{
${ }^{16}$ While our model analyzes speculative portfolio positions given prices, a more general model should also derive risk premia in equilibrium. The well know difficulty in this step is that market prices reveal information, and therefore reduce the importance of agents' private signal. Interestingly, however, the empirical evidence on the IMF catalytic effect on asset prices is consistent with many of our results. For instance, Mody and Saravia (2003) find the IMF programs improve market access and the frequency of bond issuance, and lower spreads. IMF programs seem to contain the negative effect on spread of high export variability. Finally, the IMF influence is larger for intermediate level of the fundamentals, while the catalytic role of the IMF increases with the size of its programs. The link between these empirical findings and our theoretical conclusions are apparent (see Mody and Saravia (2003) for a review of the empirical literature).
} 
Note that the difference (if any) between total resources and debt obligations is the country $G N P$, available to domestic consumption:

$$
\begin{aligned}
Y & =\max \left\{R(1-z) I+(\Lambda-x D)_{+}-(1-x) D-L_{+}, 0\right\} \\
& =\max \left\{R I\left[1-\frac{z \kappa}{1+\kappa}\right]+M-D, 0\right\}
\end{aligned}
$$

whereas we make use of the notation convention $(\Lambda-x D)_{+}=\max \{\Lambda-x D, 0\} .{ }^{17}$ Note that $G N P$ and domestic consumption are zero in the event of default. In what follows, we take $G N P$ as a measure of national welfare.

\subsection{Payoffs and information}

In this subsection we describe the payoffs and information set of fund managers and the IMF. The objective function of the government will be introduced later on, in the subsection on moral-hazard distortions.

As in Rochet and Vives (2002), fund managers face a structure of payoffs that depend on taking the "right decision". When the country does not default, rolling over loans in period 1 is the right thing to do, and yields a benefit that is higher than withdrawing - the difference in utility between rolling over debt and withdrawing is equal to a positive constant $b$. When the country defaults, managers who do not withdraw in the interim period make a mistake and therefore pay a cost. The difference in utility between rolling over loans and withdrawing is negative, and set equal to $-c$.

Different from previous literature, we model an international institution providing liquidity, the International Monetary Fund ( IMF) as an additional player that is large in the world economy. In specifying the IMF objective function, we want to capture the idea that the IMF is concerned with the inefficiency costs associated with early liquidation, but cannot provide subsidized loans or grants to a country with bad fundamentals. The payoff of the managing

\footnotetext{
${ }^{17}$ To derive the expression in the second line $(1)$ note that the term $(\Lambda-x D)_{+}$is zero when liquidation costs are positive. Adding and subtracting $x D$ we get

$$
Y=R(1-z)+x D-D-L_{+}
$$
}

whereas accounting for liquidation costs we have

$$
x D-D-L_{+}=M-D+\frac{R I \kappa}{1+\kappa} .
$$


board of the IMF is isomorphic to that of private fund managers: if the country ends up not defaulting, lending $L$ is the right thing to do. By providing liquidity rather than denying it, the IMF gets a benefit $B$. If the country defaults, instead, the IMF loses money when lending. Relative to doing nothing, the benefit from providing liquidity is negative and equal to $-C$.

Note that, in the above specification of payoffs, the utility for funds' managers and the IMF is independent of the extent of default. Our analysis thus abstracts from distributional issues between the country and the creditors, as well as between private creditors and the IMF, that arise in debt crises.

As regards the stochastic process driving the fundamental, we assume that the rate of return $R$ is distributed normally with mean $R_{j}$ and variance $1 / \rho$. The mean $R_{j}$ - with $j=A, N$ - depends on the "effort" of the government, as analyzed later on in the paper. In period 0 , the distribution of $R$ (but the value of its mean) is common knowledge in the economy; $R$ is realized in the interim period.

In the interim period, international fund managers do not know the true $R$ but each of them receives a private signal $\widetilde{s}_{i}$ such that

$$
\widetilde{s}_{i}=R+\varepsilon_{i}
$$

whereas individual noise is normally distributed with precision $\alpha$ and its cumulative distribution function is denoted by $G($.$) .$

By the same token, the management of the IMF also ignore the true $R$, but receive a signal $\widetilde{S}$ such that

$$
\widetilde{S}=R+\eta
$$

where $\eta$ is also normally distributed, with precision $\beta$ and its cumulative distribution function is denoted by $H($.$) .$

Now, note that the posteriors of both funds managers and the IMF will depend on public information (the prior distribution of $R$ ), private signals and on probability assigned to the event 'government took action A' (call it $p_{A}$ ). The posterior $s$ for a fund manager that gets signal $\widetilde{s}_{i}$ is equal to:

$$
s=p_{A}\left(\frac{R_{A} \rho+\widetilde{s}_{i} \cdot \alpha}{\rho+\alpha}\right)+\left(1-p_{A}\right)\left(\frac{R_{N} \rho+\widetilde{s}_{i} \alpha}{\rho+\alpha}\right)
$$


Analogously, the posterior of the IMF is:

$$
S=p_{A}\left(\frac{R_{A} \rho+\widetilde{S} \cdot \beta}{\rho+\beta}\right)+\left(1-p_{A}\right)\left(\frac{R_{N} \rho+\widetilde{S} \alpha}{\rho+\beta}\right)
$$

The interaction between private and public signals in coordination games is the focus of recent literature including Hellwig (2002) and Morris and Shin (2002b). Encompassing the main results of these papers in the context of our model would complicate the analysis considerably, without necessarily adding essential insights. To keep our work focused, we abstract from the above issue altogether. In Sections 4 and 5 below, we will proceed as in Corsetti, Dasgupta, Morris and Shin (2003) by assuming a very uninformative public signal $(\rho \rightarrow 0)$. In section 6 , instead, we will focus on government behavior, affecting the mean of the distribution of $R$. Hence, we will set $\rho$ equal to a finite value, and consider the limiting case in which private information is arbitrarily precise, although precision is not necessarily identical for funds' managers and the IMF. In either cases - $\rho \rightarrow 0$ (for $\alpha$ and $\beta$ finite) or $\alpha, \beta \rightarrow \infty$ (for $\rho$ finite)

$$
\begin{aligned}
& \lim _{\frac{\rho}{\alpha} \rightarrow 0} s_{i}=\widetilde{s}_{i} \\
& \lim _{\frac{\rho}{\beta} \rightarrow \infty} S=\widetilde{S}
\end{aligned}
$$

so that we can disregard public information in building our equilibrium. ${ }^{18}$

\subsection{Solvency and liquidity}

To illustrate the logic of the model, suppose that no early withdrawal of funds could ever occur (debt is effectively long-term), so that $x=0$. In this case, the country is solvent if the cash flow from investment is at least equal to its net debt ${ }^{19}$

$$
R I \geq D-M
$$

Thus, the minimum rate of return at which the country is solvent conditional on no liquidity drain in the interim period (the break-even rate) is

$$
R_{s}=\frac{D-M}{I} .
$$

\footnotetext{
${ }^{18}$ See Hellwig (2002) (Theorem 1) among others.

${ }^{19}$ Note that the following is true whether or not the IMF lends to the country — if it does so, the country will increase its gross stock of international safe assets in period 1, and use the additional reserves to pay back the IMF in period 2.
} 
In the presence of liquidity runs, a return on investment as high as $R_{s}$ may no longer be sufficient for the country to avoid default. Specifically, if the IMF has not lent to the country in the interim period, the country will be solvent in period 2 if and only if:

$$
R(1-z) I=R I-(1+\kappa)[x D-M]_{+} \geq(1-x) D .
$$

Denoting by $\bar{R}$ the minimum rate of return at which the country is solvent conditional on no IMF intervention, we can write:

$$
\bar{R}=R_{s}+\kappa \frac{[x D-M]_{+}}{I} \geq R_{s}
$$

With early liquidation of investment (i.e., when $x D-M>0$ ), the break-even rate must increase above $R_{s}$, as the failure of international investors to roll over their debt results in wasteful liquidation costs and hence ex-post efficiency losses.

Conversely, if the IMF intervenes in the first period, ex-post efficiency losses will be contained, and the solvency threshold for the rate of return conditional on a given $x$ will be lower. Namely, the country will be solvent if

$$
R(1-z) I=R I-(1+\kappa)[x D-M-L]_{+} \geq(1-x) D+L .
$$

Denoting by $\bar{R}_{L}$ the relevant threshold for default, we have

$$
\bar{R}_{L}=R_{s}+\kappa \frac{[x D-M-L]_{+}}{I} \geq R_{s} .
$$

IMF interventions increase the country GNP to the extent that they reduce early liquidation. It is worth noting that there are two ways in which the IMF can reduce early liquidation: directly, as the IMF provides liquidity against fund withdrawals, and indirectly, as the presence of the IMF may reduce the fund managers' willingness to withdraw for any given fundamental (lowering $x$ for any given realization of $R$ ). This latter effect is at the heart of our analysis in the following sections. ${ }^{20}$

\footnotetext{
${ }^{20}$ Default in the interim period is also possible. For this to happen, it must be the case that the speculative attack in the interim period exceeds all liquidity resources plus the liquidation value of domestic investment$$
x D \geq \frac{R I}{1+k}+M+L_{+}
$$ 


\section{Speculative runs and liquidity provision in equilibrium}

We now turn to the characterization of the equilibrium in our three-period economy for given government policies (i.e., for a given distribution of the fundamental $R$ ). According to our specification, in the interim period the IMF and the fund managers take their decisions independently and simultaneously. In effect, we envision a world in which the contingent fund $L$ initially committed by the IMF may not be available ex post, and this is understood by fund managers, who correctly compute the likelihood of IMF interventions. As mentioned above, the idea here is that the IMF will refuse to lend if, according to its information, there is no prospect to recover its loans $L$ fully — so that contingent financial assistance would turn into a subsidy. A different timing of decisions - with the IMF moving prior to private lenders — is discussed in section 7 .

At the heart of our model lies the coordination problem faced by fund managers in the interim period. Fund managers are uncertain about the information reaching all other managers and the IMF, and therefore face strategic uncertainty about their actions. But the expected payoff of each fund manager from rolling over a loan to the country depends positively on the fraction $(1-x)$ of managers not withdrawing in the interim period, as well as on the IMF willingness to provide liquidity. The IMF expected payoff from providing liquidity, in turn, depends positively on the fraction of agents who roll over their debt. Clearly, the decision by the fund managers and the IMF are strategic complements.

As in Corsetti, Dasgupta, Morris and Shin [2003] - hereafter CDMS - in our model there is a unique equilibrium ${ }^{21}$ in which agents employ trigger strategies: a fund manager will withdraw in period 1 if and only if her private signal on the rate of return of the risky investment is below some critical value $\widetilde{s}^{*}$, identical for all managers. Analogously, the IMF will intervene in support of a country in distress if and only if its own private signal is above

The minimum rate of return at which early liquidation $x$ leads to early default is

$$
\begin{aligned}
\bar{R}_{E D} & =(1+\kappa)\left[\frac{[x D-M]_{+}}{I}-\frac{L_{+}}{I}\right] \\
& =(1+\kappa) R_{s}\left[\frac{[x D-M]_{+}}{D-M}-\frac{L_{+}}{D-M}\right]
\end{aligned}
$$

where ED stands for early (period 1) default.

${ }^{21}$ The equilibrium is familiar to readers of the global-game literature. It is a Bayes Nash equilibrium in which, conditional on a player signal, the action prescribed by this player's strategy maximize his conditional expected payoff when all other players follow their equilibrium strategy. 
some critical value $\widetilde{S}^{*}$. Using the argument in CDMS, it can be shown that a focus on trigger strategies is without loss of generality, as there is no other equilibrium in other strategies. The proof is omitted, since it can be derived from the appendix A of the CDMS paper.

The equilibrium is characterized by four critical thresholds. The first two thresholds are critical values for the fundamental $R$, below which the country always defaults - one conditional on no IMF intervention, $\bar{R}$, the other conditional on IMF intervention, $\bar{R}_{L}$. The other two are the thresholds $\widetilde{s}^{*}$ and $\widetilde{S}^{*}$ for the private signal reaching the funds managers and the IMF, discussed above. In this and the next section we will assume that the public signal is arbitrarily uninformative - i.e., $\rho \rightarrow 0$, so that posteriors will coincide with private signals (see (6) and (7)). We will therefore express signals and thresholds of individual managers and the IMF in terms of these agents' posterior, denoted without tilde (i.e., $s_{i}, S, s^{*}$ and $S^{*}$ ).

Let us first derive the equations determining $\bar{R}$ and $\bar{R}_{L}$. If funds managers follow a trigger strategy with threshold $s^{*}$, the proportion of fund managers who receive a signal such that their posterior is below $s^{*}$ and hence withdraw in the first period crucially depends on the realization $R$ :

$$
x=\operatorname{prob}\left(s_{i} \leq s^{*} \mid R\right) \equiv G\left(s^{*}-R\right) .
$$

Using our definition of the threshold for failure $\bar{R}$, if the IMF does not intervene, there will be a crisis for any $R$ such that $R \leq \bar{R}$. Then, at $R=\bar{R}$ the mass of international managers that withdraw is just enough for causing the country to fail. This mass is $x=G\left(s^{*}-\bar{R}\right)$. Using (11), the first equilibrium condition - defining $\bar{R}-$ is therefore:

$$
\bar{R}=R_{s}\left[1+\kappa \frac{\left[G\left(s^{*}-\bar{R}\right) \cdot D-M\right]}{D-M}\right] .
$$

If the IMF intervenes, there will be a crisis for any $R$ such that $R \leq \bar{R}_{L}$. As above, at $\bar{R}_{L}$ the critical mass of speculator to cause debt liquidity-related problems is $x=G\left(s^{*}-\bar{R}_{L}\right)$. From (13), the threshold for failure conditional on IMF intervention $\bar{R}_{L}$ is:

$$
\bar{R}_{L}=R_{s}\left[1+\kappa \frac{\left[G\left(s^{*}-\bar{R}_{L}\right) \cdot D-M-L\right]}{D-M}\right]
$$

This is the second equilibrium condition - defining $\bar{R}_{L}$. At the thresholds $\bar{R}$ and $\bar{R}_{L}, x D$ must be greater than $M$ conditional on no IMF intervention, and greater than $M+L$ otherwise. So, 
in equilibrium

$$
\left[G\left(s^{*}-\bar{R}\right) \cdot D-M\right]>0 \quad \text { and } \quad\left[G\left(s^{*}-\bar{R}_{L}\right) \cdot D-M-L\right]>0 .
$$

It is easy to show the two equilibrium conditions above imply $\bar{R}_{L}<\bar{R} .{ }^{22}$

We now turn to the equations determining the triggers $s^{*}$ and $S^{*}$, starting from the latter. Upon receiving the signal $\widetilde{S}$, the IMF assigns probability $H\left(\bar{R}_{L}-S\right)$ to the failure of the country despite its intervention. The IMF expected payoff (denoted $\mathcal{W}_{I M F}$ ) is therefore

$$
\mathcal{W}_{I M F}=B \cdot\left(1-H\left(\bar{R}_{L}-S\right)\right)-C \cdot H\left(\bar{R}_{L}-S\right)
$$

which is decreasing in $S$. The optimal strategy consists of lending to the country if and only if this expected payoff is non-negative, that is, if and only if $S \geq S^{*}$ where $S^{*}$ is defined by

$$
S^{*}=\bar{R}_{L}-H^{-1}\left(\frac{B}{B+C}\right) .
$$

The investor's problem is more complex, as discussed in CDMS. Whether or not the IMF intervenes, the country will default for $R<\bar{R}_{L}$. So, a fund manager receiving signal $\widetilde{s}$ will assign probability $G\left(\bar{R}_{L}-s\right)$ to the event 'default regardless of the IMF's action'. However, for $R$ comprised between $\bar{R}_{L}$ and $\bar{R}$, the country will default only if the IMF fails to intervene. So, the managers' expected payoff (denoted $\mathcal{W}_{F M}$ ) from rolling over their fund in period 1 includes a term accounting for the conditional probability that the IMF fails to provide liquidity to the country, $H\left(S^{*}-R\right)$ :

$$
\begin{aligned}
\mathcal{W}_{F M}= & b\left[1-\left(G\left(\bar{R}_{L}-s\right)+\int_{\bar{R}_{L}}^{\bar{R}} g(R-s) \cdot H\left(S^{*}-R\right) d R\right)\right] \\
& -c\left(G\left(\bar{R}_{L}-s\right)+\int_{\bar{R}_{L}}^{\bar{R}} g(R-s) \cdot H\left(S^{*}-R\right) d R\right)
\end{aligned}
$$

${ }^{22}$ From (15) and (16) we have:

$$
\begin{aligned}
s^{*} & =\bar{R}+G^{-1}\left[\left(\frac{\bar{R}}{R_{s}}-1\right) \frac{D-M}{\kappa D}+\frac{M}{D}\right]= \\
& =\bar{R}_{L}+G^{-1}\left[\left(\frac{\bar{R}_{L}}{R_{s}}-1\right) \frac{D-M}{\kappa D}+\frac{M+L}{D}\right] .
\end{aligned}
$$

Taking differences:

$$
\bar{R}-\bar{R}_{L}=G^{-1}\left[\left(\frac{\bar{R}_{L}}{R_{s}}-1\right) \frac{D-M}{\kappa D}+\frac{M+L}{D}\right]-G^{-1}\left[\left(\frac{\bar{R}}{R_{s}}-1\right) \frac{D-M}{\kappa D}+\frac{M}{D}\right] .
$$

Suppose $\bar{R} \leq \bar{R}_{L}$. Then the LHS of the above equation would be less or equal to zero, while the RHS is positive. So it must be the case that $\bar{R}>\bar{R}_{L}$. 
where $g$ is the probability density function. The optimal trigger $s^{*}$ for funds' managers is implicitly defined by the zero-profit condition (in expected terms) below:

$$
\frac{b}{b+c}=G\left(\bar{R}_{L}-s^{*}\right)+\int_{\bar{R}_{L}}^{\bar{R}} g\left(R-s^{*}\right) \cdot H\left(S^{*}-R\right) d R .
$$

The appendix A2 shows that there is a unique value $s^{*}$ that solves this equation.

The four equations (15), (16), (17) and (19) in four endogenous variables $\left(\bar{R}, \bar{R}_{L}, S^{*}\right.$ and $\left.s^{*}\right)$ completely characterize the equilibrium. Note that in our equilibrium the country will always default when the realization of the fundamentals is worse than $\bar{R}_{L}$, it will never default when $R$ is above $\bar{R}$ (when $R \geq \bar{R}$, whether or not the IMF intervenes, the fundamentals are good enough for the country to withstand any speculative run in the interim period). But for $R$ comprised between $\bar{R}$ and $\bar{R}_{L}$, default may or may not occur, depending on the IMF. Analytical solutions for the general case are not available, but after identifying the relevant questions we want to address, we can resort to numerical simulations and derive some analytical results.

\section{The effect of IMF lending on the likelihood and severity of debt crises}

A distinctive feature of our global-game model is that crises have both a fundamental component and a speculative component. Not only must the rate of return be low enough for a speculative withdrawal to cause a solvency crises: withdrawals are more likely when the fundamentals are weak. The presence of an institutional lender of liquidity - even if with limited resources - affects the strategy of the fund managers. By changing the likelihood of speculative withdrawals, its presence can therefore influence the macroeconomic performance of the country.

In this section, we analyze the effects of IMF lending on the likelihood and severity of debt crises. More specifically, we can articulate our analysis addressing the following four questions: $:^{23}$

1. Does a larger availability of resources to the IMF increase the 'confidence' of the fund

\footnotetext{
${ }^{23} \mathrm{CDMS}$ analyze questions related to the first three in our list in the context of a study focused on the role of large speculative players in currency crises.
} 
managers in the country — as captured by their willingness to roll over their loans for a relatively worse signal on the state of fundamentals?

2. To what extent does IMF lending affect the likelihood of a crisis?

3. Does the precision of the information of the IMF relative to the market matter? In other words, is the impact of IMF lending stronger as its information becomes more accurate?

4. To what extent IMF lending creates moral hazard, in the sense that because of liquidity support governments and/or corporations do not take (costly) steps to reduce vulnerability to crises?

We discuss the first three questions in this section. The last question on moral hazard where our work yields the most novel result - will be analyzed in detail in the next section. Throughout our analysis, we will constrain $L$ such that $L<D-M$. Obviously, when $L$ becomes large enough to cover all possible withdrawals, liquidity is no more a concern — the break even rate is $R_{s}$.

\subsection{Size of interventions}

As regards question 1 and 2 above, we summarize our comparative static exercise by means of the following proposition:

Proposition 1 All thresholds $\left(\bar{R}_{L}, \bar{R}, s^{*}\right.$ and $\left.S^{*}\right)$ are decreasing in $L$.

Proof: see appendix.

To see how this proposition answers to question 1 , note that if a larger $L$ lower $s^{*}$, funds managers are now willing to rollover their loans for weaker private signals about fundamentals

- hence they are less aggressive in their trading. A larger IMF raises the proportion of investors who are willing to roll over their debt at any level of the fundamental. Moreover, since the rate of return is normally distributed, if $\bar{R}, \bar{R}_{L}$ and $S^{*}$ are all decreasing in $L$, the ex-ante probability of a crisis also falls with $L$. Then, the answer to question 2 is that bigger IMF interventions indeed lower the likelihood of a crisis. Observe that a lower $S^{*}$ increases the probability of the IMF intervention for each level of the fundamentals. Expected GNP correspondingly increases. 
These results lend theoretical support to the notion that an international lender of last resort increases the country's expected GNP not only through the direct effects of liquidity provision (interventions obviously reduce costly liquidation of existing capital). There is also an indirect effect on the coordination problem faced by fund managers: the possibility of interventions of size $L$ lowers the threshold at which private managers refuse to roll over their debt, to an extent that increases with the size of contingent interventions. It follows that an international lender can avoid some early liquidation even if it does not act ex post.

To enhance the comparison between our analysis and the literature (especially contributions stressing multiple equilibria and self-fulfilling runs), it is useful to look at the equilibrium in our model when the precision of signals becomes arbitrarily large. When the errors $\varepsilon_{i}$ go to zero, all private signals are arbitrarily close to the true fundamental $R$. Yet, signals are not common knowledge and agents still face strategic uncertainty about each other actions (i.e., they do not 'know' each other action in equilibrium). But with $\alpha, \beta \rightarrow \infty$, except in a measure-0 set in which the fundamental happens to be arbitrarily close to the threshold $\bar{R}_{L}$, either everybody withdraws early and the IMF does not intervene or nobody withdraws early. In this limiting case, there is no heterogeneity in managers' action, and there will be (almost) no provision of liquidity in equilibrium. Thus, the prediction of our model is observationally equivalent to the model with common knowledge after Diamond and Dybvig [1983] — for a comparison, Appendix A.1 develops a D\&D version of our model.

With $\alpha, \beta \rightarrow \infty$, all the benefit of a lender of last resort come through the coordination effect (as the IMF almost never intervenes saving liquidation costs). To coordinate markets, however, the IMF need not have 'deep pockets'. A marginal increase in the size of conditional interventions $L$ lowers the threshold $s^{*}$ chosen by all agents in equilibrium (at which $x$ endogenously drops from 1 to 0$)$.

\subsection{The precision of IMF information}

Above we have characterized the equilibrium when private signals become arbitrarily precise. Question 3 raises the interesting issue regarding the role, if any, of the relative precision of the information of the IMF. This is a central issue in the analysis of the influence of large players in currency crises by CDMS, as these players are usually believed to act on superior information. 
In our context, the main interest is in the equilibrium effect of improving the quality of IMF information.

What happens when the IMF private information becomes more accurate? The following proposition synthesize our result.

Proposition 2 An increase in the IMF information precision decreases all thresholds.

Proof: see appendix ${ }^{24}$

Ceteris paribus, a higher precision of information by the IMF increases the willingness by fund managers to roll-over their loans to the country, and reduces the probability of default. Intuitively, if the IMF has the ability to estimate the state of the country fundamentals arbitrarily well, funds' managers need not worry about idiosyncratic noise in the IMF intervention decisions. Provided that the IMF's objective function is common knowledge, private investors understand its strategy (lending to possibly illiquid but not to insolvent countries). At the margin, increasing the accuracy of IMF information makes them more willing to lend, because they will be confident that the IMF assessment of the fundamentals will not be far away from their own assessment - they can therefore expect the IMF to intervene when they believe that the state of the economy grant intervention.

\subsection{A remark on portfolio managers' incentives}

In our model, the strategies of all agents are endogenous in equilibrium. The parameters describing investors' payoffs affect more than the fund managers' own investment thresholds: because of their influence on the market coordination problem, these parameters also affect the equilibrium strategy by the IMF.

In our analysis, we focus on IMF's incentives and strategy. Yet our framework can also shed light on the general equilibrium effect of corporate governance and managers' behavior. By way of example, the next proposition establishes a link between the structure of incentives faced by the funds' managers, and the likelihood of IMF interventions. Recall that in our model $b$ is the net gain in utility when a manager rolls over debt and the country is solvent, relative

\footnotetext{
${ }^{24}$ CDMS show an analogous result for the limiting case when all players have arbitrarily accurate information. Our proposition generalize their result.
} 
to withdrawing in the first period. The same net utility is negative and equal to $-c$ when the country defaults. Formally:

Proposition 3 All thresholds $\left(\bar{R}_{L}, \bar{R}, s^{*}\right.$ and $\left.S^{*}\right)$ are decreasing in $b$ and increasing in $c$.

Proof: see appendix.

Intuitively, a weaker reward to successful long-term investment makes fund managers more wary about rolling over their credit. This in turn leads the IMF to be more cautious in providing liquidity. The likelihood of debt default correspondingly increases in equilibrium.

This proposition touches upon a topic extensively discussed by the literature, regarding the reason why rewards to long-term investment strategies may be perceived as weak by managers. For instance, funds' performance may be assessed against industry-wide benchmarks, so that individual managers may be reluctant to take positions at odds with those benchmarks, even if these position may have good risk-adjusted payoffs in the long term. Although our example is admittedly stylized, it shows the potential importance of general equilibrium analysis of these issues.

\section{$6 \quad$ Liquidity and moral hazard}

In the previous section we have shown that the ex-ante GNP of the country - our measure of national welfare - is increasing in the size of the IMF for any given distribution of the fundamental. Yet, moral-hazard considerations may invalidate such conclusion, since liquidity assistance by the IMF could reduce the incentive for the government to implement costly policies that enhance the likelihood of good macroeconomic outcomes.

We now develop our framework and assume that the government can take a costly action improving the expected value of $R$ without affecting the variance of the distribution. The government decides its level of effort in period 0 , when international investors lend $D$ to the country and the IMF states the size of its contingent intervention $L$. The action by the government is not observed at any point (and the IMF cannot make the provision of liquidity conditional on it).

For simplicity, we will initially assume that the government can take one single action $A$ (say, a policy reform and fiscal adjustment) that raises $E_{0} R$ from $R_{N}$ to $R_{A}$ (let $\Delta R=R_{A}-R_{N}$ ). 
The welfare cost of undertaking action $A$ is $\Psi$. This cost falls on the government only, and is motivated by exogenous considerations, say, electoral costs of reforms and fiscal adjustment. The government welfare function is

$$
\mathcal{W}=\mathcal{U}-\Psi=E_{0} Y-\Psi
$$

where $\mathcal{U}$ is the utility of the domestic representative agent. Note that $\mathcal{W}$ does not coincide with social welfare $\mathcal{U}$, that is measured by expected GNP only. At this end of this section, we will show that our main results carry over to a more general setup.

\subsection{Liquidity provision and government behavior}

It is convenient to focus our analysis on the limiting case when private signals become arbitrarily precise. An important reason is that, as the government affects the mean of the prior distribution, we need to relax the assumption of an uninformative public signal and conduct our analysis by setting a strictly positive $\rho$. With arbitrarily precise private information, we can do so without unnecessarily complicating the analysis. A second reason is that, as we have shown in the previous section, the case of arbitrarily precise private information brings the results of our model more closely into line with the predictions of models after Diamond-Dybvig, and therefore makes it easier to stress core differences between the two. Namely, with $\alpha \rightarrow \infty$, all agents will take the same action in equilibrium for almost all realizations of $R$ (except when

$\mathrm{R}$ happens to be arbitrarily close to $\bar{R}_{L}$ ), so that in equilibrium there will be no heterogeneity (but the equilibrium is unique) and no partial liquidation (except in a measure-zero set). Thus, the utility of the government conditional on its action simplifies to:

$$
\begin{aligned}
\lim _{\alpha \rightarrow \infty} \mathcal{W}(A) & =\int_{\bar{R}_{L}}^{\infty}[R \cdot I+M-D] f\left(R \mid R_{A}\right) d R-\Psi \\
\lim _{\alpha \rightarrow \infty} \mathcal{W}(N) & =\int_{\bar{R}_{L}}^{\infty}[R \cdot I+M-D] f\left(R \mid R_{N}\right) d R
\end{aligned}
$$

Notably, the integrand in the above expressions does not depend on the liquidation cost $\kappa$ the set of realizations of $R$ at which funds' withdrawals in period 1 lead to partial liquidation has measure zero. But the above expression is not independent of $\kappa$ : in fact the lower extreme of integration (i.e., the threshold $\bar{R}_{L}$ ) crucially depends on this cost. 
Taking the difference in government welfare with and without the costly action we obtain:

$$
\begin{aligned}
\lim _{\alpha \rightarrow \infty} \mathcal{W}(A)-\mathcal{W}(N) \equiv & \Delta \mathcal{W}=I \cdot \Delta R \cdot\left(1-F\left(\bar{R}_{L} \mid R_{N}\right)\right) \\
& +\int_{\bar{R}_{L}}^{\bar{R}_{L}+\Delta R}[R \cdot I+M-D] \cdot f\left(R \mid R_{A}\right) d R-\Psi
\end{aligned}
$$

In deciding whether to undertake the action $A$, the government compares the utility costs of a reform $\Psi$ with the gains in expected GNP that come both in terms of higher average realization of $R$ (first term on the RHS), and in terms of lower expected liquidation costs (second term on the RHS) because of the drop in the probability of a run on debt.

As the size of the IMF impacts the limits of integration, depending on parameter values there may be some critical $L$ at which the government switches policy. The question is therefore how the net gain from the action $A, \Delta \mathcal{W}$, vary with the size of the IMF, $L$. The answer is stated by the following proposition.

Proposition $4 \Delta \mathcal{W}$ is decreasing in $L$ if and only if $\bar{R}_{L}<\frac{R_{A}+R_{N}}{2}$.

Proof: using our proposition (1), we know that for a given distribution of the fundamental, $\bar{R}_{L}$ is decreasing in $L$. We can therefore study the response of $\Delta \mathcal{W}$ to changes in $\bar{R}_{L}$, rather than in $L$. We have:

$$
\frac{d(\Delta \mathcal{W})}{d \bar{R}_{L}}=\left(\bar{R}_{L} I+M-D\right)\left[f\left(\bar{R}_{L} \mid R_{N}\right)-f\left(\bar{R}_{L} \mid R_{A}\right)\right]
$$

The first term in brackets is non-negative (because $\left(\bar{R}_{L} I+M-D\right)=\left(\bar{R}_{L}-R_{s}\right) I$ and $\left.\bar{R}_{L} \geq R_{s}\right)$ but the second term can have either sign. As $R_{A}>R_{N}$, we have that

$$
f\left(\bar{R}_{L} \mid R_{N}\right)>f\left(\bar{R}_{L} \mid R_{A}\right) \Leftrightarrow \bar{R}_{L}<\frac{R_{A}+R_{N}}{2}
$$

which is the condition for a positive $\frac{d(\Delta \mathcal{W})}{d \bar{R}_{L}}$.

Suppose that $\bar{R}_{L}$ is lower than both $R_{N}$ and $R_{A}$ - implying that the probability of a crisis is less than 50 percent irrespective of government behavior. In this case, the difference on the RHS is positive: a decrease in $\bar{R}_{L}$, corresponding to a more abundant liquidity provision $L$, reduces the extra-utility a government gets for taking the costly action $A$.

This case is illustrated by Figure 1-a. ${ }^{25}$ In equilibrium, the position of $\bar{R}_{L}$ in this figure is

\footnotetext{
${ }^{25}$ Parameters employed: $R_{A}=1.25, R_{N}=1.20, \sigma_{R}=0.08$ and $\bar{R}_{L}=1.15$.
} 
such that the density at $\bar{R}_{L}$ is higher conditional on $R_{N}$ than conditional on $R_{A}$. A decrease in $\bar{R}_{L}$ will therefore reduce the gain in expected GNP from 'good' government behavior.

(a)
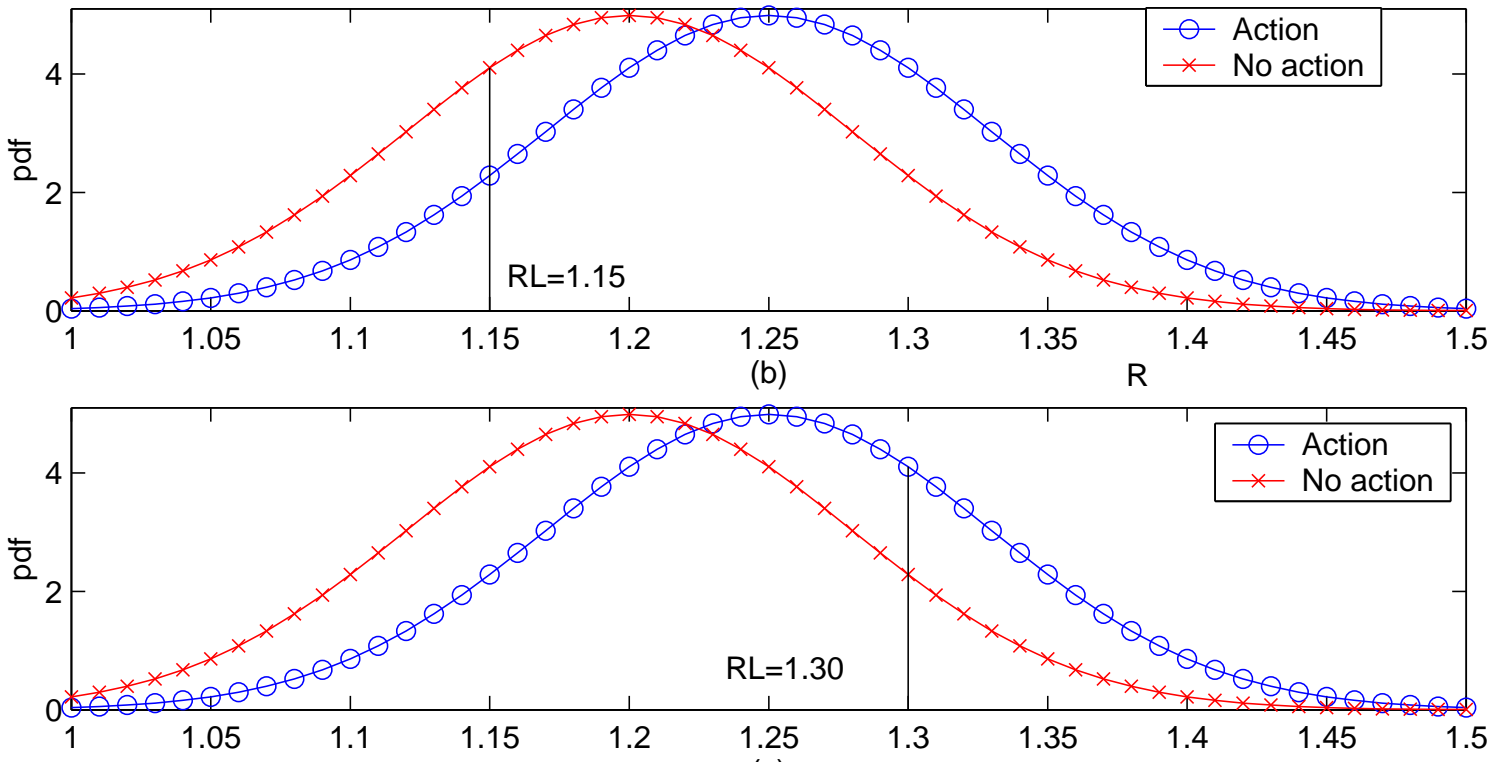

(c)

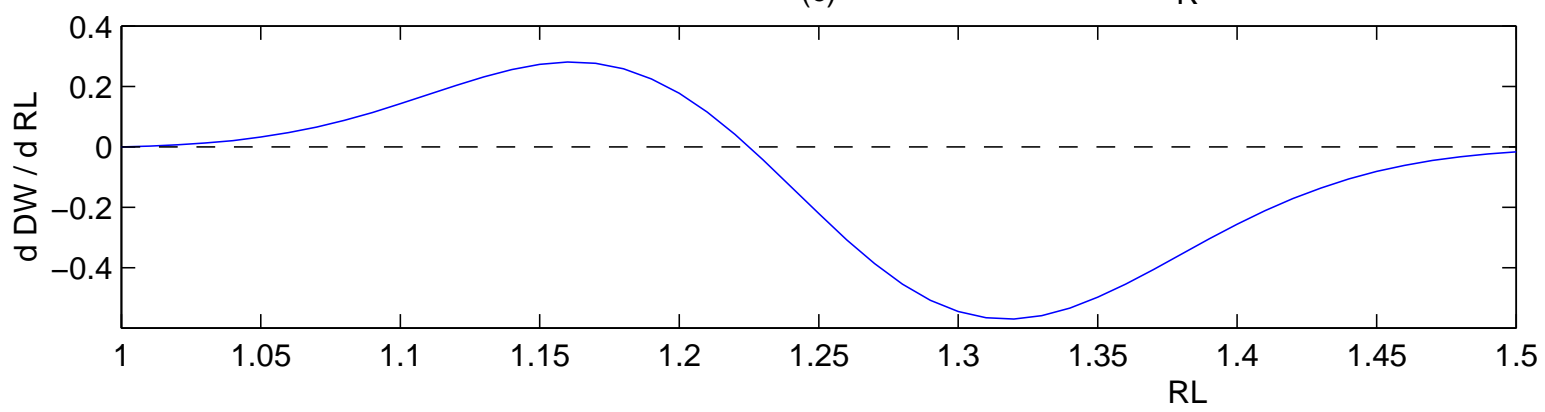

Figure 1: Government's decision: $\Delta \mathcal{W}$ and $\bar{R}_{L}$

The equilibrium in Figure 1-a is consistent with the commonly held view of moral hazard distortions from liquidity provision. The argument underlying the traditional view is that the cost $\Psi$ is high while the chances of a favorable macroeconomic outcome are good despite no government effort. In this case, additional liquidity provision is more likely to be helpful if the government does not take the costly action, so it further reduces the incentive for good behavior. However, our proposition make it clear that what is drawn in figure 1-a is not the only possible scenario. 


\subsection{Liquidity provision as an incentive for the government to 'do the right thing'}

We are now ready to state a key result of our analysis. Suppose that the country fundamentals are relatively weak, in the sense that the ex-ante probability of a crisis is more than 50 percent even if the government chooses the costly action $A$. Then, according to proposition $4, \Delta \mathcal{W}$ will be increasing in $L$.

Intuitively, if - at some given $L$ - the probability of a failure is relatively high, the government has little incentive to bear the costs of improving the macro outcome: the chance that a good outcome will materialize is low whether or not it exerts any effort. In this case, additional liquidity provision is more likely to be helpful if the government takes the costly action, so it increases the incentives for good behavior. By reducing the likelihood of runs and their costs in terms of forgone output, larger support by an international lender of last resort improves the trade off between the cost of government effort and the related improvement in the country's GNP. Whether the government chooses the action $A$ in equilibrium will then depend on whether the net utility gain from action $A$ exceeds its cost. To illustrate this case, in Figure 1-b the equilibrium $\bar{R}_{L}$ is drawn to the right of $R_{A}$. Clearly, a decrease in $\bar{R}_{L}$ raises the gains in expected GNP from the government action $A$.

Figure 1-c, instead, shows how the derivative of $\Delta \mathcal{W}$ with respect to $\bar{R}_{L}$ varies with the level $\bar{R}_{L} \cdot{ }^{26}$ In looking at this figure, recall that $\bar{R}_{L}$ is monotonically decreasing in the size of IMF intervention $L-$ so what the graph shows is the marginal effect of $L$ on government incentives at different level of liquidity assistance. If $\bar{R}_{L}$ is small (i.e., $L$ is large), the difference $\left[f\left(\bar{R}_{L} \mid R_{N}\right)-f\left(\bar{R}_{L} \mid R_{A}\right)\right]$ is positive and so is $\frac{d(\Delta \mathcal{W})}{d \bar{R}_{L}}$. For intermediate values of $\bar{R}_{L}$ (and $L$ ), the ex-ante probability of a crisis gets higher. When $\bar{R}_{L}$ is large enough, $f\left(\bar{R}_{L} \mid R_{N}\right)<$ $f\left(\bar{R}_{L} \mid R_{A}\right)$ and $\frac{d(\Delta \mathcal{W})}{d \bar{R}_{L}}$ is negative. In this case, by lowering $\bar{R}_{L}$, additional liquidity provision (larger $L$ ) actually strengthens the incentive for the government to take the costly action.

Relative to the traditional view, global-game models point to a different and intriguing possibility, one of strategic complementarity between the actions by the IMF and the domestic government (see the discussion of a similar result in Morris and Shin (2002)). When the exante probability of a crisis is high, the payoff to the government from action $A$ is increasing

\footnotetext{
${ }^{26}$ Parameters employed: $R_{A}=1.25, R_{N}=1.20, \sigma_{R}=0.08, I=1, M=0.2, D=1.2$.
} 
in $L$. Note that also the payoffs of the IMF is increasing in the action $A$ undertaken by the government.

In closing this section, we note that our conclusion remains unchanged when government welfare depends on GDP, rather than GNP - this is equivalent to assume that the amount paid to foreigners is independent of the realization of $R$, perhaps because there are other resources in the economy in addition to the payoffs of domestic investment $I$. By discussing this case, we stress that our results are not driven by the assumption of "limited liability" for the economy as a whole. Even if the government cares about GDP, a marginal increase in the size of the IMF would still reduce $\bar{R}_{L}$, producing marginal saving on liquidation costs. Its effect on the incentives to take the costly action $A$ depends on the likelihood that it will benefit the government in either situation (conditional on choosing $R_{A}$ or $R_{N}$ ). The intuition is exactly the same as when government cares about GNP — we present some calculation in the appendix A.7 to shed further light on this issue.

\subsection{Policy tradeoffs and the optimal size of L: numerical examples}

The properties of our model can be illustrated by means of four numerical examples, all depicted in Figure 2. To draw this figure, we adopt the parameter values shown in table 1, and set $D=1.2$ and $I=1$. For each example, we plot $\mathcal{W}(A), \mathcal{W}(N)$ and $\mathcal{W}(A)+\Psi$ against different values of $L$.

As shown above, the government chooses the costly action whenever $\mathcal{W}(\mathcal{A})>\mathcal{W}(\mathcal{N})$. The country's GNP is therefore $\mathcal{W}(\mathcal{N})$ if the action is not taken, and $\mathcal{W}(A)+\Psi$ if the action is taken. Thus, the various graphs in figure 2 show for which values of $L$ the government takes the costly action $A$, as well as the country expected GNP, as a function of $L$.

Figures 2-a and 2-b illustrate the case in which a large ILOLR unambiguously creates moral hazard distortions. Comparing $\mathcal{W}(A)$ with $\mathcal{W}(N)$ : the former exceeds the latter - i.e., governments prefer to take the costly action - only for relatively low values of $L$, between 0 and (approximately) 0.20. Liquidity provision in excess of this value creates a clear incentive for the government not to act. To trace the behavior of expected GNP for different levels of $L$, compare $\mathcal{W}(A)+\Psi$ with $\mathcal{W}(N)$. Increasing the size of the IMF contingent interventions above 0 at first raises expected $G N P$ monotonically along $\mathcal{W}(A)+\Psi$. At $L$ around 0.20 , however, the 
Table 1: Value of the parameters in figure 2

\begin{tabular}{|c|cccc|}
\hline figure & 2 -a & 2 -b & 2 -c & 2 -d \\
\hline$\kappa$ & .3 & .25 & .25 & .25 \\
$M$ & .25 & .20 & .20 & .20 \\
$\Psi$ & .06 & .05 & .045 & .05 \\
$b$ & 2 & 1 & 1 & 1 \\
$c$ & 10 & 10 & 10 & 10 \\
$B$ & 2 & 2 & 2 & 2 \\
$C$ & 10 & 10 & 10 & 10 \\
$R_{A}$ & 1.18 & 1.25 & 1.18 & 1.12 \\
$R_{N}$ & 1.16 & 1.22 & 1.15 & 1.065 \\
$\sigma_{R}$ & .03 & .05 & .05 & .05 \\
\hline
\end{tabular}

moral hazard distortion kicks in, determining a discrete drop in expected GNP and national welfare to $\mathcal{W}(N)$. Conditional on $R_{N}$, providing more liquidity assistance has again a positive effect on expected GNP.

Thus, in a global sense, there could be different trade-offs between liquidity provision and moral hazard. In Figure 2-b, the country $G N P$ is at a maximum when liquidity provision is just below the level at which the government would give up the costly action $A$. Globally, moral hazard distortions are more important than the costs of liquidity crises. Conversely, in Figure 2-a, the country $G N P$ is highest for high values of $L$ despite moral hazard distortions. Liquidity costs in this case are more important than the output costs due to moral hazard.

Figure 2-c illustrates the possibility of strategic complementarity between IMF lending and government policies towards solvency. In this figure the tradeoff between liquidity and moral hazard vary with $L$. For sufficiently low values of $L, \mathcal{W}(A)<\mathcal{W}(N)$ and the government does not undertake any action because it is discouraged by bleak prospects of success. For intermediate level of liquidity support, however, the government welfare becomes higher conditional on undertaking the action $A$. Liquidity provision eventually becomes excessive. For levels of $L$ in excess of 0.4 , once again $\mathcal{W}(A)<\mathcal{W}(N)$ : the government does not exert any effort, and the country's expected GNP falls. Note that, relative to Figure 2-b, the only parameter change consists of decreasing both $R_{A}$ and $R_{N}$ by a few percentage points - enough to worsen 
(a)

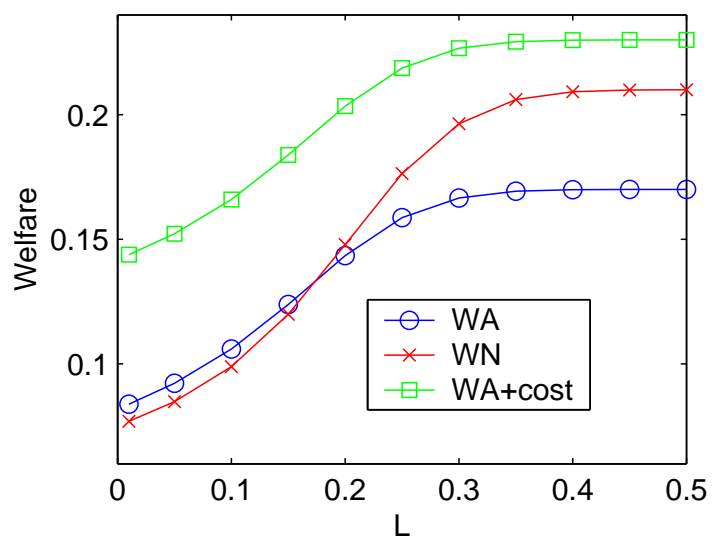

(c)

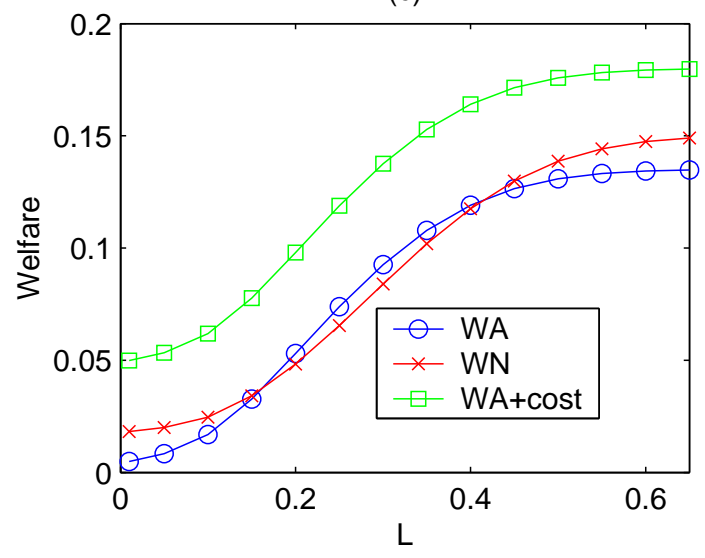

(b)

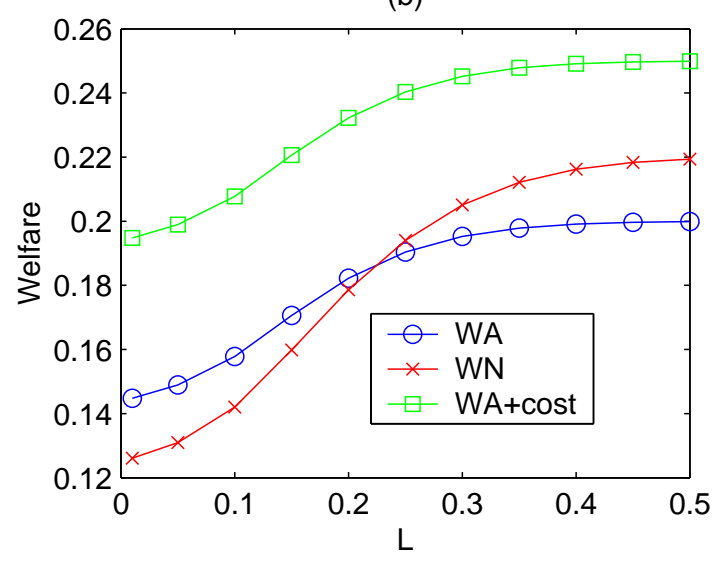

(d)

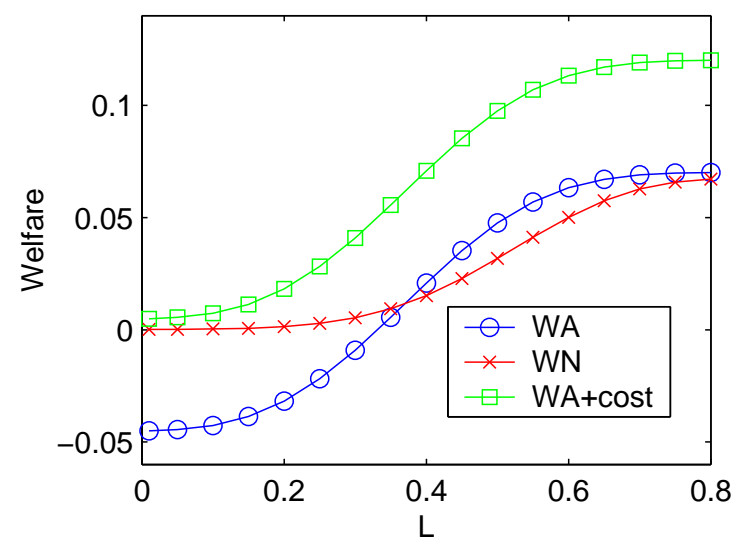

Figure 2: Policy tradeoffs

the macroeconomic outcome in such a way that, within some range of the fundamental, the government would not undertake any costly policy without liquidity assistance by the IMF.

Relative to Figure 2-c, in Figure 2-d we further reduce both $R_{A}$ and $R_{N}$, while allowing for a larger difference $\Delta R$. In figure 2-d, government welfare conditional on the costly action is actually higher than $\mathcal{W}(N)$ if the IMF provides sufficiently large contingent funds. The country GNP is always higher conditional on $A$ : globally, there is no trade off between liquidity provision and moral hazard.

These considerations may be useful as building blocks towards a normative study of the optimal size of IMF interventions. As apparent from figure 2, local governments like the highest possible level of liquidity assistance by the IMF. Once moral hazard considerations are 
taken into account, however, the level of liquidity assistance preferred by policymakers may not be the one that maximizes expected GNP and national welfare. Since the welfare cost $\Psi$ does not fall on the country's citizens, these may prefer a low level to a large level of $L$. This is the case in the economy depicted by Figure 2-b.

The level of $L$ preferred by the IMF need not coincide with either the level of $L$ preferred by national governments, or the level preferred by the country's citizens. In our specification, the structure of IMF preferences penalizes any loss of funds in case of national default, yet as a simplification the penalty from lending liquidity to crisis countries is exogenously given. Thus, for any given disutility from loosing its loans to the country — the main concern of the IMF is whether or not to limit $L$ below its feasible level, as a way to mitigate moral-hazard distortions that could raise discretely the likelihood of a crisis.

\subsection{Moral hazard with a continuous set of actions for the government}

We conclude this section by reconsidering our analysis of moral hazard in a more general framework. Let $\Delta R$ denote policy effort, raising linearly the expected value of the fundamental, i.e., $E_{0} R=R_{0}+\Delta R$. Policy effort entails a utility cost $\Psi(\Delta R)^{\nu} / \nu$, affecting the government only. Thus, assuming that the noise in private signal is arbitrarily small $(\alpha \rightarrow \infty)$, the policy problem is to maximize:

$$
\begin{aligned}
\lim _{\alpha \rightarrow \infty} \mathcal{W}(\Delta R) & =\int_{\bar{R}_{L}}^{\infty}[R \cdot I+M-D] f\left(R \mid R_{0}+\Delta R\right) d R-\frac{\Psi(\Delta R)^{\nu}}{\nu} \\
& =\int_{\bar{R}_{L}-\Delta R}^{\infty}[(R+\Delta R) \cdot I+M-D] f\left(R \mid R_{0}\right) d R-\frac{\Psi(\Delta R)^{\nu}}{\nu}
\end{aligned}
$$

Taking the derivative with respect to $\Delta R$, we get:

$$
\begin{aligned}
\frac{d \mathcal{W}(\Delta R)}{d \Delta R} & =\left(\bar{R}_{L} I+M-D\right) f\left(\bar{R}_{L}-\Delta R \mid R_{0}\right)+\int_{\bar{R}_{L}-\Delta R}^{\infty} I \cdot f\left(R \mid R_{0}\right) d R-\Psi(\Delta R)^{\nu}(26) \\
& =\left(\bar{R}_{L}-R_{s}\right) \operatorname{If}\left(\bar{R}_{L}-\Delta R \mid R_{0}\right)+I\left(1-F\left(\bar{R}_{L}-\Delta R \mid R_{0}\right)\right)-\Psi(\Delta R)^{\nu-1}
\end{aligned}
$$

It is easy to show that, for $\nu>1$ and reasonable values of $\Psi$, our results for the binaryaction case still apply. Namely, when ex-ante odds of a crisis are high enough, the government chooses little or no policy effort. By reducing the ex-ante probability of a crisis, a larger $L$ would then raise the government incentive to choose a higher effort $\Delta R$. Conversely, when the ex-ante probability of a run is small, additional liquidity provision induces the government to reduce $\Delta R$. 
(a) $\mathrm{nu}=2$

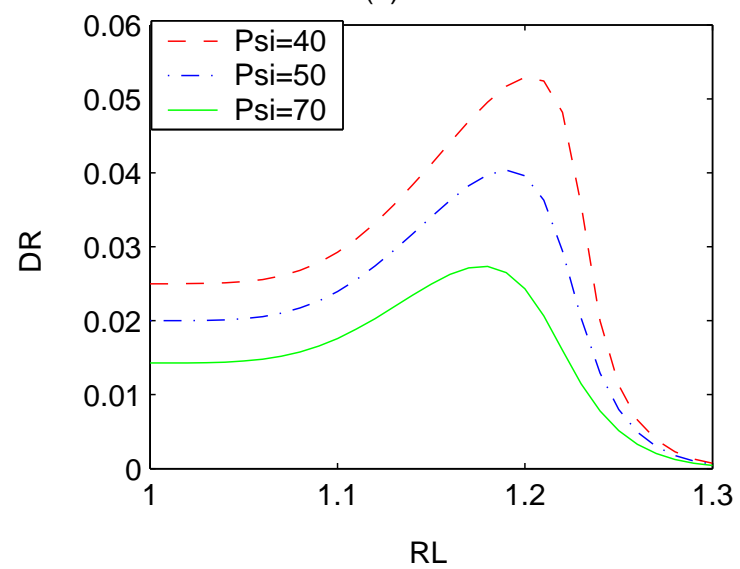

(c) $\mathrm{nu}=3$

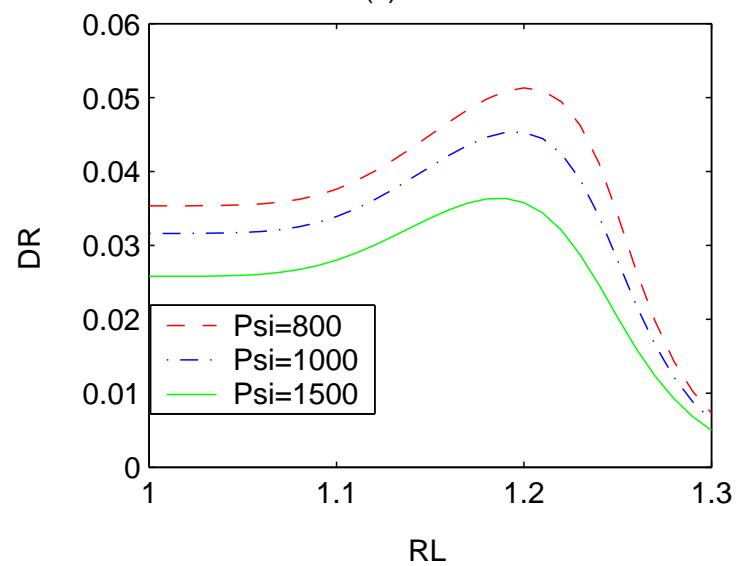

(b) $\mathrm{nu}=1.2$

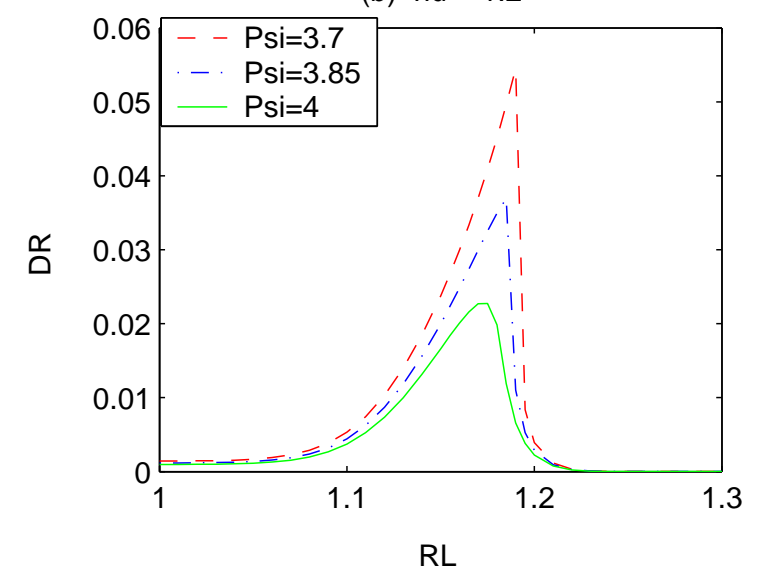

(d) $\operatorname{Pr}$ (crisis) if $\mathrm{DR}=0$

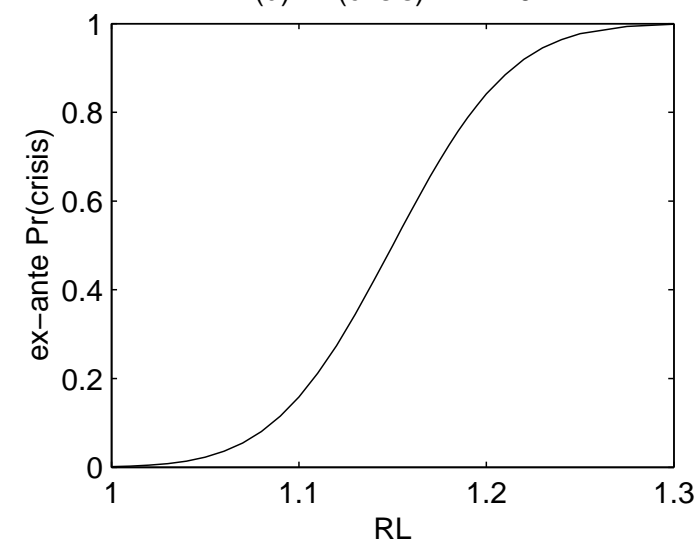

Figure 3: Continuous set of actions for the government

These results are illustrated by Figures 3-a,b,c, which plot the optimal effort level $\Delta R$ as a function of $\bar{R}_{L}$, for $\nu$ equal to 2, 1.2 and 3, respectively. Figure 3-d, instead, shows the ex-ante odds of a crisis as a function of $\bar{R}_{L}$ conditional on $\Delta R=0 .{ }^{27}$ The first three graphs appear quite similar: effort $(\Delta R)$ is increasing in $\bar{R}_{L}$ up to a point (around 1.18 or 1.20, depending on parameters' values), after which it is decreasing in $\bar{R}_{L}$. Note that the elasticity of $\Delta R$ falls with $\nu$.

\footnotetext{
${ }^{27}$ Parameters used in the figures: $R_{s}=1, R_{0}=1.15, \sigma_{R}=0.05, I=1$.
} 


\section{Extensions of the model}

\subsection{Seniority of IMF loans}

The IMF may require a 'preferred creditor status' as a precondition to provide liquidity. A realistic variant of our model could then allow IMF loans to have priority over private loans. In this case, the solvency threshold for the return on the risky investment that is relevant for the IMF decision is

$$
R(1-z) I=R I-(1+\kappa)[x D-M-L]_{+} \geq L
$$

Provided that $[x D-M-L]>0$ we can write

$$
\begin{aligned}
\bar{R}_{I M F}= & (1+\kappa) \frac{[x D-M]}{I}-\kappa \frac{L}{I}= \\
& R_{s}\left[(1+\kappa) \frac{[x D-M]}{D-M}-\kappa \frac{L}{D-M}\right]
\end{aligned}
$$

The international liquidity provider keeps lending up the point in which the country has just enough resources to repay $L$.

There are two effects to consider. On the one hand, as the IMF gets a larger share of the country's resources in case of default, it is more willing to intervene. This effect makes a crisis less likely. On the other hand, conditional on a crisis, private investors are juniors relative to the IMF, so that the return on their investment is lower. They should therefore be less willing to roll over debt. This effect makes a crisis more likely.

What are the overall implications of allowing for IMF seniority? We will show below that our framework fully captures the first effect, while providing a framework for a heuristic discussion of the second. Assuming, as in section 4, that $\rho \rightarrow 0$, the following equations characterize the equilibrium when the IMF loans have seniority) - all variables in this case are denoted with a prime $\left({ }^{\prime}\right)$ :

$$
\begin{gathered}
\bar{R}^{\prime}=R_{s}\left[1+\kappa \frac{\left[G\left(s^{*}-\bar{R}^{\prime}\right) \cdot D-M\right]}{D-M}\right] \\
\bar{R}_{L}^{\prime}=R_{s}\left[1+\kappa \frac{\left[G\left(s^{\prime *}-\bar{R}_{L}^{\prime}\right) \cdot D-M-L\right]}{D-M}\right] \\
S^{\prime *}=\bar{R}_{I M F}^{\prime}-H^{-1}\left(\frac{B}{B+C}\right)
\end{gathered}
$$




$$
\begin{gathered}
\bar{R}_{I M F}^{\prime}=R_{s}\left[(1+\kappa) \frac{\left[G\left(s^{\prime *}-\bar{R}_{I M F}^{\prime}\right) \cdot D-M\right]}{D-M}-\kappa \frac{L}{D-M}\right] \\
\frac{b}{b+c}=G\left(\bar{R}_{L}^{\prime}-s^{\prime *}\right)+\int_{\bar{R}_{L}^{\prime}}^{\bar{R}^{\prime}} g\left(R-s^{\prime *}\right) \cdot H\left(S^{\prime *}-R\right) d R
\end{gathered}
$$

There are now 5 equations and 5 variables, instead of 4 equations in 4 variables. Note that the derivatives of the above expressions with respect to $L$ are all negative, and, as in the version of our model without IMF seniority, $\bar{R}_{L}^{\prime}<\bar{R}^{\prime}$. We can show that:

$$
\bar{R}_{I M F}^{\prime}<\bar{R}_{L}^{\prime}
$$

We hereafter state our result:

Proposition 5 When the IMF has seniority, there is a positive coordination effect that reduces all thresholds making the crisis less likely (ex-ante): $s^{* \prime}<s^{*}, \bar{R}^{\prime}<\bar{R}, \bar{R}_{L}^{\prime}<\bar{R}_{L}$.

Proof: see appendix.

This proposition confirms our previous result, that more liquidity provision (induced by IMF seniority) tends to increase the willingness of fund managers to roll over their debt, and decrease the likelihood of crises. But note that the proposition holds agents' payoffs constant - i.e., the penalty for lending to a defaulting country does not change even if the private return conditional on default are now lower. Realistically this penalty should become higher when the IMF debt has seniority. From proposition 2 we know that an increase in the penalty parameter $c$ will tend to raise all thresholds - i.e., move them in the opposite direction relative to what predicted by proposition (5). An important extension of the model thus consists of specifying a tighter link between managers' payoffs and portfolio returns, as to disentangle the role of other factors, such as risk aversion, in determining optimal intervention policies.

\subsection{Sequential moves}

An important question in our study concerns the consequences of letting the IMF move before the withdrawal decision by funds managers. In this section we briefly discuss the case in which funds managers take their portfolio decision being informed about the IMF intervention. A similar question is addressed by CDMS and especially by Amil Dasgupta in a series of papers - to which we refer for the analytical aspects of the issue. 
Consider the following amendment of our setup: private signals reach the IMF and funds' managers simultaneously, but the interim period is split into two subperiods: early and late. The payoff structure is the same as before: in particular, payoffs do not depend on moving early or late in the interim period.

CDMS start their analysis with an observation about timing incentives in the new game - an observation that also applies here. Under the assumption that payoffs are independent of the timing of the move, individual funds managers with no market power will always have an incentive to move late rather than early. They know that they will have no benefit from signalling: as they are too small to influence the actions by other players, there is no point in taking an early position in the market. On the other hand, they can learn something by waiting: they can learn whether the IMF has committed liquidity funds $L$, which also conveys information about the IMF private signal.

The same argument implies that the IMF will always have a weak incentive to move first. As funds managers always wait, the IMF will never learn anything by waiting - no private decision will be taken early in the interim period. On the other hand, by moving early, the IMF can influence the behavior of the market. There is a clear benefit from moving first. As in CDMS, the IMF is assumed to move early.

CDMS and related work by Dasgupta show that this game admits an equilibrium in trigger strategies similar to the one analyzed in Section 4, except that now funds managers have two triggers for their signal: one conditional on IMF intervention, the conditional on no IMF intervention. Notably, as before, the IMF intervenes if and only if its signal is good enough relative to an optimally selected thresholds for its signal. But this means that, by observing the IMF move, funds managers will learn whether the signal reaching the IMF is above or below such a threshold. If the precision of IMF information is high enough, the IMF move will be quite informative about the state of the fundamentals. One can build examples in which funds managers will disregards their private signal, and just conform to the IMF move: they will rollover debt if the IMF opens contingent credit lines to the country, and withdraw otherwise. This is dubbed "strong herding behavior" in Dasgupta (1999). If however the IMF precision of information is not high, funds managers will form their posterior without ignoring their private information. An IMF intervention will of course discourage some of the withdrawals, without 
necessarily eliminating the possibility of a speculative crisis. $^{28}$

\section{Conclusions}

As the main results of the model have been stated in the introduction, we devote our conclusion to some policy-related consideration, and a brief discussion of perspectives for future research.

The debate on reforming the international financial architecture has long suffered from the lack of analytical studies comparing liquidity support (bailouts) with different forms of private sector involvement. The merit of policy analyses embracing the extreme paradigm of multiple instantaneous equilibria and self-fulfilling crises consists in stressing that disruptive speculative runs need not be inconsistent with rational individual behavior - i.e., rational expectations are not sufficient to rule out speculative threats to macroeconomic and financial stability. Self-fulfilling runs, however, are not the exclusive cause of crises, so that excessive emphasis on liquidity may severely bias policy design. Moreover, these analyses have severe limits in dealing with a number of important policy issues, especially regarding the trade-off between liquidity provision and moral hazard, but also as regards transparency and information accuracy.

As opposed to the main prescription from these models, the possibility of self-fulfilling runs does not necessarily justify a full bailout solution to financial crisis. First, 'catalytic finance' is more likely to work in the case of pure speculative crises: a partial bailout may well be sufficient to restore confidence. Second, and most important, crises are usually caused by a combination of weak fundamentals, poor policies and speculative runs. Official finance may create wrong policy/effort incentives deriving from expectations of a bailout.

The model presented in this paper contributes to take the policy debate a step further. Our model sheds light on possible channels through which the IMF 'catalytic finance' may work, i.e., channels through which the presence of contingent liquidity provision raises the number of international investors willing to rollover their loans to a country for any given fundamental. But this makes clear that catalytic finance cannot be effective when the macroeconomic outlook turns out to be very weak - as private signals become correspondingly worse, massive withdrawal would cause a crisis whether or not the IMF intervenes.

\footnotetext{
${ }^{28}$ The equilibrium sketched above (and fully characterized by Dasgupta (1999) and CDMS), however, is not necessarily unique.
} 
Second, our model emphasizes the possibility that liquidity assistance do not produce moral hazard distortions. Rather, under some circumstances, it may turn out to be key for wellintentioned governments to undertake appropriate policies, as the IMF could at least in part shield the country from self-fulfilling speculative runs. In other words, by insuring against liquidation costs caused by self-fulfilling speculation, the IMF could raise the expected gains from reforms, therefore making them more attractive relative to their costs. Other papers based on global games has provided examples of this principle, notably Morris and Shin (2002).

While pointing to this possibility, this literature makes clear that moral hazard distortions are likely to be the dominant concern in setting up facilities providing international liquidity support. As is well known, there are moral hazard distortions at different levels (i.e., at the level of the debtor country - its private and public sector - as well as of international investors). The reform of the international financial architecture cannot but address the issue of their involvement in bearing the cost of a crisis - vis-a-vis the provision of liquidity as an insurance against speculation risk.

This paper and Morris and Shin (2002) show that the literature on global games is particularly effective to shed light on these issues. Morris and Shin reach conclusions similar to ours in a stylized one-period model, we articulate them in a bank-run framework. Moreover, we model explicitly the payoffs of the IMF and domestic policy makers, showing how the equilibrium allocation depends on the incentive structure faced by the main players (private and public). We show how our approach can account for a number of realistic features of the international financial architecture - in some cases requiring the specification of a more articulated framework. It is reasonable to expect that this literature will soon have further important developments as regards both theory and policy analysis.

In the text of our paper, we have already pointed out important directions for future research building on the framework of our model. These include a study of the optimal size of liquidity support, the implications of a preferred creditor status for the IMF, and the optimal timing and conditionality of IMF interventions. We have argued that the analysis of these issues crucially depends on the specification of payoffs for both the IMF and the international investors which is a natural important development of our model.

But there are many other dimensions that future research could explore. For instance, the true type of government (conservative, reformist, radical and so on) is likely to be only 
imperfectly observed. We have seen that, depending on the parameters of the model, liquidity may either complement reforms and good policies, or induce moral hazard distortions. As the preferences of the government may well be relevant in determining which scenario is faced by the IMF, allowing for imperfectly credible policymakers will crucially influence the optimal timing, size and conditionality of IMF interventions and the success of catalytic approach that could be reconsidered in the context of model with pooling/separating equilibria. In this respect, empirical studies (reviewed by Cottarelli and Giannini (2002)) suggest that the catalytic approach tends to fail when adjustment policies are imperfectly credible.

The structure of our economy is highly stylized - in the tradition of bank run studies and many recent contributions on international illiquidity and vulnerability to crises. There could be important lessons to be learned from model in which the public and the private sectors are treated separately, specifying both a banking and a nonfinancial corporate sector. By the same token, we focused on a real model, abstracting from the link between financial and currency crises. Extending the model as to analyze this link could contribute to our understanding of dollarization.

By the same token, we mostly focused on bailouts. The literature suggests that, when large bailout funds are not available, coercive bailins in the form of debt standstill and suspensions may work at times. Under which conditions, bailins and debt suspensions dominate catalytic solutions? Moreover, most of the recent debate on architecture reform has centered on comparing alternative debt restructuring mechanisms. This is the policy debate contrasting a "statutory approach" (SDRM) to a "contractual approach" (collective action clauses) to debt restructuring. Our analytical apparatus can be modified to address such issues - Haldane et al. (2002) provide an example of work in this direction.

There is great need for comprehensive empirical studies of catalytic finance, to which our paper can provide a suitable theoretical framework. Looking at the policy experience in the last decade, the catalytic approach was initially adopted by the IMF in each of the main emerging market economies that experienced a crisis (Mexico, Thailand, Indonesia, Korea, Russia, Brazil, Turkey, Argentina to name the most important ones - see Cottarelli and Giannini (2002)). The approach succeeded in some cases (Mexico, Brazil); it did not succeed in others (Russia, Argentina, Indonesia). The 1997/98 crisis in Korea is an example of partial success. Catalytic finance cum policy adjustment was not enough to ensure voluntary market debt rollover; the 
collective action problem of creditors was however solved by a semi-coercive bailin (with the coercive restructuring of short-term cross-border interbank lines). Empirical studies of why and to what extent catalytic finance may work has great importance to guide the current policy debate on the reform of international financial architecture, whereas exceptional IMF finance is perhaps the hottest issue at stake.

\section{A Appendix}

\section{A.1 Multiple equilibrium benchmark}

The coordination effect that is captured by global-game models cannot be accounted for by models of international lender of last resort after Diamond and Dybvig [1983]. This framework assumes common knowledge of the signal, and in equilibrium each agent conditions his choice on the speculative position taken by all other agents in the economy. Because of this strong assumption, multiple equilibria are possible for intermediate range of fundamentals, whereas a country defaults if a speculative run occurs, is solvent otherwise. In this range, a debt crisis occurs when each fund manager believes (i.e., knows) that all other fund managers will also refuse to roll over their debt. There is no heterogeneity in managers' action: either everybody attacks (i.e., $x=1$ ), or nobody attacks (i.e., $x=0$ ). In this appendix we study a version of our model without private information - in the tradition of the bank-run literature stressing multiple equilibria and self-fulfilling runs. Without private information, IMF interventions of limited size can lower, at the margin, the break-even rate of return conditional on the whole market denying credit (i.e., $x=1$ ), but not the break-even rate conditional on nobody withdrawing their funds $(x=0)$. Most important, they are irrelevant in determining whether the market rollover or withdraw loans (i.e., whether $x=0$ or $x=1$ ) - see the analysis in Corsetti Pesenti and Roubini (2002) — unless the IMF has enough resources to bailout the country completely.

Assume that in our model all investors and the IMF have complete information about $R$. We are interested in understanding the main features of this economy, and identify the values of the fundamental $R$ corresponding to which the equilibrium is not unique. The equilibrium is characterized by the following partition of $R$. Suppose that $L$ is small relative to the external 
financing gap of the country. If $R<R_{s}$, the country is insolvent and there is a unique equilibrium with $x=1$ and a crisis. If $R>\operatorname{Max}\left[R_{s}, R_{s}(1+\kappa)-\kappa \frac{L}{I}\right]$ the country has enough liquidity to pay everybody and there is a unique equilibrium with $x=0$ and no crisis. If $R_{s}<R<R_{s}(1+\kappa)-\kappa \frac{L}{I}$, there are 2 equilibria, depending on whether investors attack the country or keep lending to it. Note that, when the IMF has sufficiently large resources relative to the next stock of short-term liability of the country, the equilibrium is unique: a crisis occurs if and only if $R<R_{s}$.

To see this, consider first an equilibrium with a crisis. In equilibrium, rational investors will all withdraw in the first period $(x=1)$ and the IMF does not intervene. It is easy to see that, in equilibrium, no investor will have an incentive to deviate and lend to the country. In our specification, a single investor of infinitesimal size makes no difference in the amount of resources that the country will have in period 2. So, an individual agent have an incentive to deviate if and only if $R$ is sufficiently high that the country will be left with non-negative resources in the second period, independently of the run. But if the $R$ is large enough, a crisis cannot be an equilibrium outcome, and nobody attacks.

Things are slightly different for the IMF, as this agent is not infinitesimal, i.e., its intervention makes a difference as regards the end-point resources of the country. Namely, the IMF has an incentive to deviate if the country has non-negative resources in the second period conditional on its intervention. If all agents withdraw $(x=1)$ and the IMF intervenes, equation (12) tells us that the country will have non-negative resources in the second period if $R>\bar{R}_{x=1}$, where $\bar{R}_{x=1}$ is given by:

$$
\bar{R}_{x=1} I-(1+\kappa)[D-M-L]_{+}=L
$$

Now there are two cases to consider, depending on the size of the IMF. If $L<D-M$, which means that the IMF endowment of liquidity in not large enough to fill the whole external financing gap, we have:

$$
\bar{R}_{x=1}=R_{s}(1+\kappa)-\kappa \frac{L}{I}
$$

Conversely, if $L>D-M$, the IMF can solve the liquidity problem by itself, and we have

$$
\bar{R}_{x=1}=R_{s}
$$

Note that $\bar{R}_{x=1}$ depends on $L$. If $L$ is limited, the IMF can contain the costs of a speculative 
run over some range of fundamentals. If $L$ is not limited, instead, liquidity is not an issue, and a crisis only occurs if the country is insolvent.

Consider now a scenario without a crisis: rational agents do not withdraw $(x=0)$ and the IMF intervenes. An equilibrium without crisis is consistent with rational expectations if the return on investment plus the money from the IMF is enough to pay all creditors and the IMF in the second period - in other words, there are no liquidation costs. Nobody has an incentive to deviate if $R>\bar{R}_{x=0}$, which is given by:

$$
I \bar{R}_{x=0}+L=D-M+L
$$

which yields:

$$
\bar{R}_{x=0}=R_{s}
$$

As there are no early withdrawals, the IMF is not saving any liquidation cost, so the equilibrium with no crisis exists if and only if the country is solvent. Note that $\bar{R}_{x=0}$ does not depend on $L$.

So, according to the multiple-equilibria framework, the IMF can solve the liquidity problem if and only if it has deep pockets. Otherwise, it has a limited impact on the range of fundamentals for which multiple equilibria are possible. Observe that, in equilibrium, either (a) all investors withdraw, the IMF does not intervene and there is a crisis, or (b) all investors roll over their debts, the IMF intervenes and there is no crisis.

In this model, there is no endogenous mechanism of equilibrium selection. Which equilibrium will investors choose? The solution usually adopted by the literature consists in attributing arbitrary probabilities $\xi$ to a sunspot event selecting between equilibria. Note that this solution has many well-known conceptual problems: why would everybody pick the same action? what is the sunspot? But even abstracting from these particular issues, consider the goal of analyzing catalytic finance and moral hazard distortion within the framework sketched above. The sunspot probabilities $\xi$ must be known ex-ante. The equilibrium would depend crucially on $\xi$, but not on preference parameters $b, c, B, C$. Conditional on $\xi$, the IMF will have an effect only on the threshold $\bar{R}_{x=1}$, but not on the other thresholds. It will play no role in the equilibrium selection (unless this role is posited by assumption). All the above problems are avoided in our formulation. 


\section{A.2 Uniqueness and existence of equilibrium}

We have seen in the main text that the equilibrium value of $s^{*}$ is determined by the following equation:

$$
\frac{b}{b+c}=G\left(\bar{R}_{L}-s^{*}\right)+\int_{\bar{R}_{L}}^{\bar{R}} g\left(R-s^{*}\right) \cdot H\left(s^{*}-R\right) d R
$$

We want to show that there is a unique value that solves this equation. Define $w=R-s^{*}$, $\bar{w}=\bar{R}-s^{*}$, and $\bar{w}_{L}=\bar{R}_{L}-s^{*}$ (where clearly $\bar{w}>\bar{w}_{L}$ ). Changing variables in equation (19) and using (17) we get:

$$
G\left(\bar{w}_{L}\right)+\int_{\bar{w}_{L}}^{\bar{w}} g(w) \cdot H\left(\bar{w}_{L}-w-H^{-1}\left(\frac{B}{B+C}\right)\right) d w-\frac{b}{b+c}=0
$$

Key to our proof is that the RHS of this equation is monotonically increasing in $\bar{w}$ and $\bar{w}_{L}$, and both $\bar{w}$ and $\bar{w}_{L}$ in turn are monotonically increasing in $s^{*}$. To see why, note that increasing $\bar{w}_{L}$ is equivalent .... As regards $\bar{w}_{L}$, substituting (16) in the definition of this variable we can write

$$
-\bar{w}_{L}-\frac{\kappa R_{S} \cdot D}{D-M} G\left(\bar{w}_{L}\right)-s^{*}+\text { constant }=0
$$

Differentiating

$$
\frac{\partial \bar{w}_{L}}{\partial s^{*}}=\frac{1}{1+\frac{\kappa R_{S} \cdot D}{D-M} g\left(\bar{w}_{L}\right)}>0
$$

By the same token

$$
\frac{\partial \bar{w}}{\partial s^{*}}=\frac{1}{1+\frac{\kappa R_{S} \cdot D}{D-M} g(\bar{w})}>0
$$

just as in CDMS. Thus, for sufficiently large $s^{*}$ the LHS of (35) is positive, while it is negative for sufficiently small $s^{*}$. Since the LHS is continuous in $s^{*}$, there is a unique solution to (35). Once $s^{*}$ is uniquely determined, $S^{*}$ follows from (17).

\section{A.3 Proof of proposition 1}

This appendix proves proposition 1. Differentiating equations (15) and (16) and rearranging, we get:

$$
\begin{gathered}
\frac{d s^{*}}{d L}=\left(1+\frac{1-M / D}{R_{s} \cdot \kappa \cdot g\left(s^{*}-\bar{R}\right)}\right) \cdot \frac{d \bar{R}}{d L} \\
\frac{d s^{*}}{d L}=\left(1+\frac{1-M / D}{R_{s} \cdot \kappa \cdot g\left(s^{*}-\bar{R}_{L}\right)}\right) \cdot \frac{d \bar{R}_{L}}{d L}+\frac{1}{g\left(s^{*}-\bar{R}_{L}\right)}
\end{gathered}
$$


To ease notation, define $\zeta_{1}$ and $\zeta_{2}$ as follows

$$
\begin{aligned}
\zeta_{1} & =\left(1+\frac{1-M / D}{R_{s} \cdot \kappa \cdot g\left(s^{*}-\bar{R}\right)}\right)^{-1} \\
\zeta_{2} & =\left(1+\frac{1-M / D}{R_{s} \cdot \kappa \cdot g\left(s^{*}-\bar{R}_{L}\right)}\right)^{-1}
\end{aligned}
$$

Note that $\zeta_{1}, \zeta_{2} \in(0,1)$.

Now, define $w=R-s^{*}, \bar{w}=\bar{R}-s^{*}$, and $\bar{w}_{L}=\bar{R}_{L}-s^{*}$. Using (36) and (37) we have:

$$
\begin{gathered}
\frac{d \bar{w}}{d L}=-\left(1-\zeta_{1}\right) \frac{d s^{*}}{d L} \\
\frac{d \bar{w}_{L}}{d L}=-\left(1-\zeta_{2}\right) \frac{d s^{*}}{d L}-\frac{\zeta_{2}}{g\left(\bar{w}_{L}\right)}
\end{gathered}
$$

Changing variables in equation (19) and using (17) we get:

$$
\frac{b}{b+c}=G\left(\bar{w}_{L}\right)+\int_{\bar{w}_{L}}^{\bar{w}} g(w) \cdot H\left(\bar{w}_{L}-w-H^{-1}\left(\frac{B}{B+C}\right)\right) d w
$$

Differentiating 40 and rearranging terms:

$$
\frac{d \bar{w}}{d L} \zeta_{3}+\frac{d \bar{w}_{L}}{d L} \zeta_{4}=0
$$

where:

$$
\begin{gathered}
\zeta_{3}=g(\bar{w}) H\left(\bar{w}_{L}-\bar{w}-H^{-1}\left(\frac{B}{B+C}\right)\right)>0 \\
\zeta_{4}=g\left(\bar{w}_{L}\right)\left(\frac{B}{B+C}\right)+\int_{\bar{w}_{L}}^{\bar{w}} g(w) h\left(\bar{w}_{L}-w-H^{-1}\left(\frac{B}{B+C}\right)\right) d w>0
\end{gathered}
$$

This yields:

$$
\frac{d s^{*}}{d L}=-\frac{\zeta_{2} \zeta_{4}}{g\left(\bar{w}_{L}\right)\left[\left(1-\zeta_{1}\right) \zeta_{3}+\left(1-\zeta_{2}\right) \zeta_{4}\right]}<0
$$

Using (36), (37) and (17) we get that:

$$
\frac{d \bar{R}}{d L}<0, \frac{d \bar{R}_{L}}{d L}<0 \text { and } \frac{d S^{*}}{d L}<0
$$

which completes the proof. 


\section{A.4 Proof of Proposition 2}

Let $\Phi$ be the standard normal distribution. Then, equation (17) can be written as:

$$
\Phi\left(\sqrt{\beta+\rho}\left(S^{*}-\bar{R}_{L}\right)\right)=\frac{B}{B+C}
$$

Differentiating with respect to the precision of IMF information $(\beta)$, we get:

$$
\phi\left(\sqrt{\beta+\rho}\left(S^{*}-\bar{R}_{L}\right)\right) \cdot\left[\sqrt{\beta+\rho}\left(\frac{d S^{*}}{d \beta}-\frac{d \bar{R}_{L}}{d \beta}\right)+\frac{S^{*}-\bar{R}_{L}}{2 \sqrt{\beta+\rho}}\right]
$$

Defining $w_{S}^{*}=S^{*}-s^{*}$, using $\bar{w}_{L}$ as defined above and rearranging, we obtain:

$$
\sqrt{\beta+\rho} \frac{d w_{S}^{*}}{d \beta}=\sqrt{\beta+\rho} \frac{d \bar{w}_{L}}{d \beta}-\frac{\left(w_{S}^{*}-\bar{w}_{L}\right)}{2 \sqrt{\beta+\rho}}
$$

Moreover, as above:

$$
\begin{aligned}
\frac{d \bar{R}}{d \beta} & =\zeta_{1} \frac{d s^{*}}{d \beta} \\
\frac{d \bar{R}_{L}}{d \beta} & =\zeta_{2} \frac{d s^{*}}{d \beta}
\end{aligned}
$$

So:

$$
\begin{aligned}
\frac{d \bar{w}}{d \beta} & =-\left(1-\zeta_{1}\right) \frac{d s^{*}}{d \beta} \\
\frac{d \bar{w}_{L}}{d \beta} & =-\left(1-\zeta_{2}\right) \frac{d s^{*}}{d \beta}
\end{aligned}
$$

Differentiating (19), using (41), (42), (43) and rearranging, we get:

$$
\frac{d s^{*}}{d \beta}=\frac{\int_{\bar{w}_{L}}^{\bar{w}} g(w) h\left(w_{S}^{*}-w\right)\left(\bar{w}_{L}-w\right) d w}{2 \sqrt{\beta+\rho}\left[\left(1-\zeta_{1}\right) \zeta_{3}+\left(1-\zeta_{2}\right) \zeta_{5}\right]}<0
$$

where

$$
\zeta_{5}=g\left(\bar{w}_{L}\right)\left(\frac{B}{B+C}\right)+\int_{\bar{w}_{L}}^{\bar{w}} g(w) h\left(\bar{w}_{L}-w-H^{-1}\left(\frac{B}{B+C}\right)\right) \sqrt{\beta+\rho} d w>0
$$

Finally, using (41), (42), (43), we obtain:

$$
\frac{d \bar{R}_{L}}{d \beta}, \frac{d \bar{R}}{d \beta}, \frac{d S^{*}}{d \beta}<0
$$

which concludes our proof. 


\section{A.5 Proof of Proposition 3}

Here, we show that $s *, S *, \bar{R}$ and $\bar{R}_{L}$ depend negatively on $b$ and positively on $c$. As above, we get that:

$$
\begin{aligned}
\frac{d \bar{R}}{d b} & =\zeta_{1} \frac{d s^{*}}{d b} \\
\frac{d \bar{R}_{L}}{d b} & =\zeta_{2} \frac{d s^{*}}{d b}
\end{aligned}
$$

Changing variables in the same way, we get that:

$$
\frac{d s^{*}}{d b}=-\frac{c}{(b+c)^{2}} \frac{1}{\zeta_{3}\left(1-\zeta_{1}\right)+\zeta_{4}\left(1-\zeta_{2}\right)}<0
$$

Using (44), (45) and (17) we get that:

$$
\frac{d \bar{R}}{d b}<0, \frac{d \bar{R}_{L}}{d b}<0 \text { and } \frac{d S^{*}}{d b}<0
$$

which completes the proof.

Analogously,

$$
\frac{d s^{*}}{d c}=\frac{b}{(b+c)^{2}} \frac{1}{\zeta_{3}\left(1-\zeta_{1}\right)+\zeta_{4}\left(1-\zeta_{2}\right)}>0
$$

and also:

$$
\frac{d \bar{R}}{d c}>0, \frac{d \bar{R}_{L}}{d c}>0 \text { and } \frac{d S^{*}}{d c}>0
$$

\section{A.6 Proof of Proposition 5}

Equations (15) and (16) are identical to equations (29) and (30). A bit of algebra shows that (check the proof for the derivatives with respect to $L$ ):

$$
s^{\prime *} \geq s^{*} \Rightarrow\left(\bar{R}_{L}^{\prime}-s^{*}\right) \leq\left(\bar{R}_{L}-s^{*}\right) \text { and }\left(\bar{R}^{\prime}-s^{\prime *}\right) \leq\left(\bar{R}-s^{*}\right)
$$

Moreover,

$$
s^{*}<s^{*} \Leftrightarrow \bar{R}^{\prime}<\bar{R} \Leftrightarrow \bar{R}_{L}^{\prime}<\bar{R}_{L}
$$

Now, suppose that $s^{\prime *} \geq s^{*}$.

From equations (33) and (19), we have that: 


$$
\begin{gathered}
G\left(\bar{R}_{L}-s^{*}\right)+\int_{\bar{R}_{L}}^{\bar{R}} g\left(R-s^{*}\right) \cdot H\left(\bar{R}_{L}-H^{-1}\left(\frac{B}{B+C}\right)-R\right) d R= \\
G\left(\bar{R}_{L}^{\prime}-s^{*}\right)+\int_{\bar{R}_{L}^{\prime}}^{\bar{R}^{\prime}} g\left(R-s^{*}\right) \cdot H\left(\bar{R}_{I M F}^{\prime}-H^{-1}\left(\frac{B}{B+C}\right)-R\right) d R
\end{gathered}
$$

Using relations (34) and (46), we get a contradiction that proves our claim.

\section{A.7 Liquidity provision with no 'limited liability'}

Assume that the government cares about GDP — and that there are additional resources in the economy to pay international investors. We have:

$$
\begin{aligned}
\lim _{\alpha \rightarrow \infty} \mathcal{W}(A) & =\int_{0}^{\bar{R}_{L}}\left[\frac{R \cdot I}{1+\kappa}+M-D\right] f\left(R \mid R_{A}\right) d R \\
& +\int_{\bar{R}_{L}}^{\infty}[R \cdot I+M-D] f\left(R \mid R_{A}\right) d R-\Psi \\
\lim _{\alpha \rightarrow \infty} \mathcal{W}(N) & =\int_{0}^{\bar{R}_{L}}\left[\frac{R \cdot I}{1+\kappa}+M-D\right] f\left(R \mid R_{N}\right) d R \\
& +\int_{\bar{R}_{L}}^{\infty}[R \cdot I+M-D] f\left(R \mid R_{N}\right) d R
\end{aligned}
$$

The difference in government's welfare is:

$$
\begin{aligned}
\Delta \mathcal{W} & =\int_{0}^{\bar{R}_{L}}\left[\frac{R \cdot I}{1+\kappa}+M-D\right]\left[f\left(R \mid R_{A}\right)-f\left(R \mid R_{N}\right)\right] d R \\
& +\int_{\bar{R}_{L}}^{\infty}[R \cdot I+M-D]\left[f\left(R \mid R_{A}\right)-f\left(R \mid R_{N}\right)\right] d R-\Psi
\end{aligned}
$$

The marginal effect of a change in $\bar{R}_{L}$ is:

$$
\frac{d(\Delta \mathcal{W})}{d \bar{R}_{L}}=\bar{R}_{L} I \cdot \frac{\kappa}{1+\kappa}\left[f\left(\bar{R}_{L} \mid R_{N}\right)-f\left(\bar{R}_{L} \mid R_{A}\right)\right]
$$

Therefore, the sign of the marginal effect of $L$ in this case is the same as in equation (23).

\section{References}

[1] Allen, Franklin and Douglas Gale (2000), "Financial Contagion," The Journal of Political Economy 108, No. 1, February, pp. 1-33. 
[2] Allen, Franklin and Douglas Gale (2000) "Optimal Currency Crises", unpublished mimeo, NYU, April.

[3] Allen, Franklin and Douglas Gale (2001), "Comparative Financial Systems", MIT Press.

[4] Bryant, John (1980) "A Model of Reserves, Bank Runs, and Deposit Insurance", Journal of Banking and Finance, 4, pp.335-44.

[5] Bulow, Jeremy and Kenneth Rogoff (1989) "Sovereign Debt: Is to Forgive to Forget?" American Economic Review, Vol. 79, No.1, March.

[6] Carlsson, H. and E. van Damme (1993) "Global Games and Equilibrium Selection," Econometrica 61, 989-1018.

[7] Chang R. and A. Velasco (1999), "Liquidity Crises in Emerging Markets: Theory and Policy", NBER Macroeconomic Annual, 11-58, MIT Press.

[8] Cole, Harold and Patrick Kehoe (1998) "Models of Sovereign Debt: Partial Versus General Reputations", International Economic Review 39, No. 1, February, pp. 55-70.

[9] Corsetti Giancarlo, Amil Dasgupta, Stephen Morris and Hyun Song Shin (2003), "Does One Soros make a difference? A theory of currency crises with Large and Small traders", Review of Economic Studies, forthcoming

[10] Corsetti Giancarlo, Pesenti Paolo and Roubini Nouriel (2002), "The role of large traders in currency crises", in "Preventing currency crises in emerging markets" edited by Edwards and Frankel, University of Chicago Press.

[11] Cottarelli and Giannini (2002), "Bedfellows, Hostages, or Perfect Strangers? Global Capital Markets and the Catalytic Effect of IMF Crisis Lending", IMF

[12] Dasgupta A. (1999) "Social Learning with Payoff Complementarities", mimeo Yale University

[13] Diamond, D. and P. Dybvig (1983) "Bank Runs, Deposit Insurance, and Liquidity", Journal of Political Economy 91, 401-419.

[14] Dooley, Michael and Sujata Verma (2001) "Rescue Packages and Output Losses Following Crises," NBER Working Paper 8315, June. 
[15] Eichengreen, Barry (1999) "Toward a New International Financial Architecture Institute for International Economics", Washington, D.C. 1999.

[16] Fischer, Stanley (1999) "On the Need for an International Lender of Last Resort", unpublished, IMF (http://www.imf.org/external/np/speeches/1999/010399.HTM)

[17] Frankel, Jeffrey and Nouriel Roubini (2001), "The Role of Industrial Country Policies in Emerging Market Crises," NBER Working Paper 8634; forthcoming in M. Feldstein (ed.) Economic and Financial Crises in Emerging Market Economies, volume published by NBER and Chicago University Press, 2002.

[18] Gai, Prasanna, Simon Hayes and Hyun Song Shin (2001) "Crisis costs and debtor discipline: the efficacy of public policy in sovereign debt crises," Bank of England Working Paper 136. http://www.bankofengland.co.uk/workingpapers/wp136.pdf.

[19] Gale, Douglas and Xavier Vives (2001) "Dollarization, Bailouts and the Stability of the Banking System", unpublished, New York University, July.

[20] Ghosal, Sayantan and Marcus Miller (2002) "Co-ordination Failure, Moral Hazard and Sovereign Bankruptcy Procedures," Bank Of England Conference on: The Role Of The Official And Private Sectors In Resolving International Financial Crises, Bank Of England, July.

[21] Goldstein Itay and Ady Pauzner (2002), "Demand Deposit Contracts and The Probability of Bank Runs", mimeo

[22] Gorton, Gary (1988) "Banking Panics and Business Cycles", Oxford Economic Papers. 40, pp.751-781.

[23] Haldane, Andrew Simon Hayes, Adrian Penalver, Victoria Saporta and Hyun Song Shin (2002), "Binding-in the Private Sector", unpublished, Bank of England, August. (http://www.bankofengland.co.uk/conferences/conf0207/bindinginps.pdf)

[24] Hellwig, Christian (2002) "Public information, provate information and the multiplicity of equilibria in coordination games" Journal of Economic Theory 107, pp.191-222. 
[25] Jacklin, Charles and Sudipto Bhattacharya (1988) "Distinguishing Panics and Information-based Bank Runs: Welfare and Policy Implications," The Journal of Political Economy 96, No. 3, June, pp. 568-592.

[26] Jeanne, Olivier (2000) "Foreign Currency Debt and the Global Financial Architecture," European Economic Review 44, pp. 719-727.

[27] Jeanne, Olivier (1999) "Sovereign Debt Crises and the Global Financial Architecture." Unpublished manuscript, International Monetary Fund, November.

[28] Jeanne, Olivier and Charles Wyplosz (2001) "The International Lender of Last Resort: How Large is Large Enough?" NBER Working Paper 8381, National Bureau of Economic Research.

[29] Jeanne, Olivier and Jeromin Zettelmeyer (2001) "International Bailouts, Moral Hazard, and Conditionality," Economic Policy 16, issue No 33, October.

[30] Krueger, Anne (2001a) "International Financial Architecture for 2002: A New Approach to Sovereign Debt Restructuring," IMF November 26, 2001. (http://www.imf.org/external/np/speeches/2001/112601.htm)

[31] Krueger, Anne (2001b) "A New Approach to Sovereign Debt Restructuring," IMF, December 20, 2001. (http://www.imf.org/external/np/speeches/2001/122001.htm)

[32] Krueger, Anne (2002) "New Approaches to Sovereign Debt Restructuring: An Update on Our Thinking," Conference on "Sovereign Debt Workouts: Hopes and Hazards" Institute for International Economics, Washington DC, April 1, 2002 (http://www.imf.org/external/np/speeches/2002/040102.htm)

[33] Kumar, Manmohan, Paul Masson, and Marcus Miller (2000) "Global Financial Crises: Institutions and Incentives," IMF Working Paper 00/105, International Monetary Fund.

[34] Meltzer Commission (2000) Report of the International Financial Institutions Advisory Commission ("Meltzer Commission"), Washington D.C.

[35] Mody and Saravia (2003) 
[36] Morris, S. and H. S. Shin (2000) "Global Games: Theory and Applications", invited paper for the Eighth World Congress of the Econometric Society, Seattle, 2000, http://www.econ.yale.edu/ ${ }^{\sim}$ smorris/seattle.pdf.

[37] Morris Stephen and Hyun Song Shin (2002), "Catalytic Finance", mimeo

[38] Morris Stephen and Hyun Song Shin (2002b), "Social value of public information", American Economic Review 92.

[39] Rogoff, Ken and Jeromin Zettelmeyer (2002) "Early Ideas on Sovereign Bankruptcy Reorganization: A Survey," IMF Working Paper 02/57, March. (http://www.imf.org/external/pubs/ft/wp/2002/wp0257.pdf)

[40] Roubini, Nouriel (2000) "Bailin, Burden-Sharing, Private Sector Involvement (PSI) in Crisis Resolution and Constructive Engagement of the Private Sector. A Primer: Evolving Definitions, Doctrine, Practice and Case Law," September 2000. (http://www.stern.nyu.edu/globalmacro/psipaper.pdf)

[41] Roubini, Nouriel (2001a) "Why should the foreign creditors of Argentina take a greater hit/haircut than the domestic ones: On the economic logic, efficiency, fairness and legality of "discriminating" between domestic and foreign debt in sovereign debt restructurings" December 14, 2001 (http://www.stern.nyu.edu/ nroubini/asia/discriminationforeigndebt.doc)

[42] Roubini, Nouriel (2001b) "Should Argentina Dollarize or Float? The Pros and Cons of Alternative Exchange Rate Regimes and their Implications for Domestic and Foreign Debt Restructuring/Reduction" December 2, 2001 (http://www.stern.nyu.edu/ nroubini/asia/argentinadollarization.doc)

[43] Roubini, Nouriel (2002a) "Private Sector Involvement in Crisis Resolution and Orderly Sovereign Debt Restructurings: The G-7/IMF Framework and the Open Unresolved Issues," March 2002, New York University.

[44] Roubini, Nouriel (2002b) "Do we need a new international bankruptcy regime? Comments on Bulow, Sachs and White," April 2002, New York University; forthcoming in the Brookings Panel on Economic Activity (http://www.stern.nyu.edu/globalmacro/bankreg.doc) 
[45] Roubini, Nouriel (2002c) "Do we need a new international bankruptcy regime? Alternative regimes for orderly sovereign debt restructurings", June 2002, New York University.

[46] Rochet JC and X Vives, (2002) "Coordination Failure and the lender of last resort: Was Bagehot right after all" mimeo.

[47] Sachs, Jeffrey (1984) "Theoretical Issues in International Borrowing," Princeton Studies in International Finance 54, Princeton University Press.

[48] Sachs, Jeffrey (1995), "Do We Need an International Lender of Last Resort," Frank D. Graham Lecture at Princeton University 8, April 20, 1995 (unpublished manuscript.(http://www.ksg.harvard.edu/cid/ciddirector/publicat.html\#Working).

[49] Taylor, John B. (2001) "Strengthening the Global Economy after September 11 the Bush Administration's Agenda", Kennedy School of Government, Harvard University, November 29, 2001.(http://www.treas.gov/press/releases/po831.htm)

[50] Taylor, John B. (2002a) "Grants and Sovereign Debt Restructuring: Two Key Elements of a Reform Agenda for the International Financial Institutions," Testimony of John B. Taylor Under Secretary of the Treasury for International Affairs before the Joint Economic Committee, February 14, 2002(http://www.treas.gov/press/releases/po1016.htm)

[51] Taylor, John (2002b) "Sovereign Debt Restructuring: A U.S. Perspective" remarks at Conference on "Sovereign Debt Workouts: Hopes and Hazards" Institute for International Economics, Washington DC, April 1, 2002. (http://www.treas.gov/press/releases/po2056.htm)

[52] Tirole, Jean (2002) "Financial Crises, Liquidity and the International Monetary System", Princeton University Press.

[53] Wallace, Neil (1988) "Another Attempt to Explain an Illiquid Banking System: The Diamond and Dybvig Model with Sequential Servicing Taken Seriously", Federal Reserve Bank of Minneapolis Quarterly Review 12, No. 4, pp. 3-16.

[54] Zettelmeyer, Jeronim (1999) "On the Short-Run Effectiveness of Official Crisis Lending", unpublished manuscript, International Monetary Fund, December. 